\title{
EFETIVIDADE DO “SALÁRIO MÍNIMO ESTADUAL”: UMA ANÁLISE VIA REGRESSÕES QUANTÍLICAS PARA DADOS LONGITUDINAIS
}

\author{
Rodrigo Leandro de Moura ${ }^{\S}$ \\ Marcelo Côrtes Neri ${ }^{\alpha}$
}

\section{RESUMO}

Em 2000, o governo federal aprovou uma lei que permitiu aos Estados fixarem pisos salariais acima do salário mínimo. Os Estados do Rio de Janeiro e Rio Grande do Sul adotaram tal lei em 2001. Utilizando dados de painel da Pesquisa Mensal de Emprego de 2000 e 2001, encontramos um baixo cumprimento da lei nestes Estados. Adicionalmente, obtivemos evidências de efeito nulo sobre o nível de emprego. Estes resultados indicam um alto descumprimento da legislação devido a uma baixa efetividade da lei, como sugerido pela teoria.

Palavras-chave: salário mínimo, legislação estadual, descumprimento da legislação, regressão quantílica para dados longitudinais.

\begin{abstract}
In 2000, the federal government approved a law that permitted the states to set wages floors above minimum wage. The states of Rio de Janeiro and Rio Grande do Sul adopted this law in 2001. We utilized panel data of Employment Monthly Survey from 2000 and 2001, and observed a low adherence to this law in these states. Furthermore, we get evidences of negligible effect on employment level. These results indicate a high legislation noncompliance due to low enforcement of the law, as suggested by the theory.
\end{abstract}

Keywords: minimum wage, state legislation, legislation noncompliance, quantile regression for longitudinal data.

JEL classification: J38, K31, C23, C29.

\footnotetext{
* Agradecemos a Raquel Sampaio, por uma versão bem preliminar deste artigo; a Carlos Eugênio da Costa e Luis Renato Lima, da EPGE/FGV; a Fernando Holanda Barbosa Filho, do IBRE/FGV; a Walter Belluzo Jr., da FEA-RP/USP; a Christiam GonzálesChávez, doutorando da EPGE/FGV, e a Fábio Reis Gomes, do IBMEC-SP, por seus comentários que ajudaram na versão atual deste artigo. Agradecemos também a Carlos Lamarche, da Universidade de Oklahoma, pela ajuda na estimação do bootstrap. E, por fim, agradecemos a Maria Fernanda S. B. de Moura por suas sugestões e ajuda na coleta de informações na Delegacia Regional do Trabalho. Os eventuais erros são de inteira responsabilidade dos autores

$\S$ Doutor em Economia pela EPGE/FGV-RJ. Professor da Graduação em Economia da FGV-RJ. Endereço para contato: Praia de Botafogo, 190, sala 1120 - Rio de Janeiro - RJ. E-mail: Rodrigo.Leandro@fgv.br.

a Chefe do Centro de Políticas Sociais (CPS/FGV) e professor da EPGE/FGV. E-mail: mcneri@fgv.br.
}

Recebido em janeiro de 2007. Aceito para publicação em maio de 2008. 


\section{INTRODUÇão}

A grande maioria da literatura que investiga os efeitos do salário mínimo considera a hipótese implícita de que as firmas cumprem totalmente a lei que fixa o salário mínimo. ${ }^{1}$ No entanto, esta é uma hipótese que nem sempre é válida, pois o cumprimento da lei pode resultar em lucros menores por parte dos empregadores.

Os modelos competitivos de livro-texto mostram que a fixação de um salário mínimo binding, ou seja, acima do salário de equilíbrio do mercado, implica uma queda no nível de emprego. Por outro lado, alguns modelos de monopsônio prevêem que um aumento pequeno do salário mínimo pode ter efeitos positivos, nulos ou negativos no nível de emprego (ALBRECHT; AXEL, 1984; BURDETT; MORTENSEN, 1989; ECKSTEIN; WOLPIN, 1990). Alguns estudos para os EUA apontam para a predominância do primeiro modelo (BROWN ET AL., 1982; BROWN, 1988; NEWMARK; WASCHER, 1992) enquanto outros estudos apontam para o segundo modelo (CARD; KRUEGER, 1994; CARD, 1992a, 1992b; KATZ; KRUEGER, 1992). No entanto, nenhum desses dois grupos de estudos e modelos analisa as implicações de um cumprimento parcial ou nulo da lei.

Assim, neste artigo, pretendemos analisar esta hipótese de cumprimento por parte dos empregadores a uma legislação que fixa um preço mínimo para a força de trabalho superior ao preço do mercado. Em particular, avaliaremos a lei dos pisos estaduais de salário. ${ }^{2}$ Tal lei foi implantada em 14 de julho de 2000 e permitiu aos Estados fixarem pisos salariais acima do salário mínimo, conferindo maiores graus de liberdade aos Estados em relação às suas finanças públicas. Apenas dois Estados optaram por estabelecer pisos salariais privados superiores ao salário mínimo na época da implantação: Rio de Janeiro (RJ) e Rio Grande do Sul (RS). Por exemplo, em 31 de dezembro de 2000, enquanto o salário mínimo federal era de 151 reais, o governo do Estado do RJ estabeleceu pisos salariais para três categorias de profissões que variavam de 220 até 226 reais.

O salário mínimo exerce uma miríade de papéis na economia brasileira. Um mesmo valor baliza, simultaneamente, ativos e inativos dos setores público e privado num País heterogêneo como o Brasil. Na verdade, a introdução desse piso salarial representa uma oportunidade privilegiada de avaliação dos impactos do salário mínimo por três motivos. Primeiro, por isolar os efeitos do salário mínimo, que atuam pelas vias do mercado de trabalho, daqueles operantes pelas vias fiscais. O objetivo é permitir que o salário mínimo do mercado de trabalho privado, regulado pela CLT, seja fixado em níveis superiores aos pisos das transferências do setor público. ${ }^{3}$ Os efeitos do salário mínimo operantes pela via fiscal são menos controversos do que os atuantes pelas vias do trabalho. O canal de atuação do salário mínimo por meio dos benefícios da previdência social, programas sociais (benefício de prestação continuada e seguro-desemprego, entre outros) ou do salário do funcionalismo podem ser avaliados diretamente. Como a magnitude do efeito pelas vias do setor público é muito superior ao do mercado de trabalho privado, a estimativa deste último efeito fica

1 O termo em inglês usado na literatura para o caso de cumprimento à lei é compliance.

2 O termo "Salário Mínimo" é constitucional e só pode ser utilizado em relação ao valor que a União fixa. Assim, o termo mais correto em termos de legislação para os "Salários Mínimos Estaduais" é “pisos estaduais de salário”.

3 Mesmo pensando em termos exclusivamente trabalhistas, um País de dimensões continentais como o Brasil, comporta uma formidável diversidade de mercados de trabalho locais. Aspectos como os hábitos de consumo, o tamanho e a composição das famílias, os preços e a produtividade variam notavelmente de uma região para outra. Logo, não se justificaria a existência de um único piso salarial. O Brasil era um dos poucos países grandes do mundo com um mínimo unificado. Países, como a Holanda, possuem mínimos regionais; nos EUA, é estadualizado; na França, é setorializado e, no Japão, é regionalizado e setorializado. 
obscurecida por efeitos de injeção de demanda associados a mudanças dos gastos públicos combinados ao salário mínimo. Segundo, quando o salário mínimo é reajustado de maneira diferenciada entre Estados, como prescreve a lei, obtemos condições superiores para testar os seus efeitos. Além dos grupos afetados pelo reajuste, teremos um grupo de controle (por exemplo, a mesma categoria profissional em outros Estados) para isolar os efeitos do salário mínimo. Finalmente, a alta magnitude do reajuste nominal concedido ao piso perante o salário mínimo, chegando a 50\%, permite estimação mais precisa dos efeitos obtidos no mercado de trabalho.

Neste artigo, apresentamos inicialmente uma avaliação da efetividade da lei de pisos estaduais de salário. Numa análise descritiva preliminar, sugere-se uma baixa concentração de rendimentos nos pisos estaduais, vis-à-vis, uma redução da acumulação de massa no salário mínimo, das ocupações definidas nas legislações estaduais fluminense e gaúcha. Esta evidência preliminar sugere algum nível de descumprimento da legislação. Assim, utilizando dados de painel da Pesquisa Mensal de Emprego (PME) de 2000 e 2001, ${ }^{5}$ para as regiões metropolitanas do Rio de Janeiro/Porto Alegre e de São Paulo (SP), analisamos o gap entre o salário mínimo e o salário do mercado dos trabalhadores ocupados nestes Estados que adotaram a lei em relação a SP (considerado como grupo de controle). Para tal análise, utilizamos uma abordagem via regressões quantílicas para dados longitudinais (KOENKER, 2004), modelo que se adequa à estrutura dinâmica da PME. Assim, a estimação deste modelo permite verificar o efeito nos quantis de rendimentos que apropriadamente seriam mais afetados pela lei (quantis binding). Os resultados apontam também para baixa efetividade da lei, dado que o aumento do diferencial salarial foi estatisticamente nulo em favor de RJ/RS. Em seguida, comparamos as variações no emprego dos trabalhadores antes e depois da mudança na legislação. Assim, encontramos evidências de efeito nulo sobre o nível de emprego, na direção contrária ao modelo convencional, dado o grande aumento salarial que a lei proporcionaria, sendo um indicativo adicional de baixa efetividade da legislação.

O artigo está organizado da seguinte forma: a Seção 2 revisa a literatura teórica e empírica sobre (des)cumprimento da legislação do salário mínimo; a Seção 3 descreve as legislações de pisos estaduais salariais; a Seção 4 descreve a base de dados e a amostra utilizada; a Seção 5 subdividese em: Subseção 5.1, que descreve a estratégia empírica utilizada; Subseção 5.2, que apresenta a avaliação descritiva da efetividade da lei; Subseção 5.3, que mostra os resultados das regressões quantílicas; Subseção 5.4, que avalia o impacto da lei sobre o nível de emprego e Subseção 5.5, que discute os resultados encontrados, concluindo, por fim, na Seção 6.

\section{LITERATURA RELACIONADA}

\subsection{Considerações teóricas}

A grande maioria da literatura que investiga os efeitos do salário mínimo considera a hipótese implícita de que as firmas vão cumprir totalmente a lei que fixa o salário mínimo. No entanto,

4 O termo efetividade empregado neste artigo se refere no sentido da lei ser enforced. No entanto, notamos que a lei dos pisos estaduais é enforceable, em termos da capacidade de ser enforced, visto que conseguimos verificar se a legislação está sendo cumprida, pois quem reporta o salário é o empregado por meio da base que utilizaremos.

5 Temos disponíveis os dados da PME somente de janeiro a julho de 2000 e do ano inteiro de 2001. 
esta é uma hipótese que nem sempre é válida, pois o cumprimento da lei pode resultar em lucros menores por parte dos empregadores. Ashenfelter e Smith (1979, daqui em diante AS), em seu artigo seminal, apresentam um modelo simples, no qual consideram que o empregador decide entre obedecer ou não a uma lei que cria um salário mínimo binding. Assim, os autores avaliam apenas o aspecto da evasão da lei, ou seja, se os empregadores pagam o salário fixado pela lei. Eles consideram uma probabilidade $\lambda$ de as autoridades pegarem e punirem o infrator e impõem uma multa fixa (exógena) a ser paga. As suas conclusões são que o incentivo a obedecer à lei é menor: (i) quanto mais distante é o salário de mercado do salário mínimo e (ii) quanto maior a elasticidade da demanda por trabalho (em valor absoluto). Portanto, as firmas que empregam trabalhadores de baixo salário e, conseqüentemente, são mais afetadas pela fixação do salário mínimo, terão maiores incentivos a desobedecerem à lei. Grenier (1982) considera uma multa endógena, que é estipulada como exatamente o gap entre o salário de mercado e o salário mínimo. No entanto, ambos os estudos ignoram o efeito da decisão de violação da lei sobre o nível de emprego.

Em um estudo posterior, Chang e Ehrlich (1985) apontam alguns erros (itens (i) e (iii) a seguir) encontrados nestes artigos, estendem a penalidade para ser um múltiplo $k$ deste gap e analisam, além do efeito do descumprimento da evasão, o impacto sobre o nível de emprego. As principais conclusões apontadas por estes autores são que: (i) uma penalidade que seja uma fração $(k \leq 1)$ do gap não constituirá um mecanismo efetivo para impedir o descumprimento; (ii) o incentivo para violação seria eliminado se a taxa de penalidade $k$ fosse determinada a um nível suficientemente alto, tal que fizesse a taxa de salário esperada maior que o salário mínimo; ${ }^{6}$ (iii) independentemente da estrutura de penalidade imposta pelas autoridades, ou seja, seja exógena ou proporcional ao gap, o incentivo ao descumprimento, se positivo, será maior quanto mais distante for o salário de mercado do salário mínimo, e (iv) a firma reduzirá o nível de emprego não apenas quando cumpre a lei, mas também quando descumpre a lei, porém mantendo acima da primeira situação. Isso ocorre porque a taxa de salário esperada que a firma se depara é maior que o salário de mercado, mas menor que o salário mínimo.

Em um estudo recente, Yaniv (2001, 2004a) estende a análise, considerando descumprimento parcial da lei, ou seja, uma firma avessa ao risco que possa descumprir a lei para uma fração de seus trabalhadores, enquanto a fração complementar recebe o salário mínimo. Assim, o empregador poderia diversificar o risco de ser pego e punido. Como evidência adicional às obtidas por Chang e Ehrlich (1985), o autor conclui que:

$$
L_{P C}=L_{C}<L_{N C}<L_{w^{*}}
$$

em que $L_{P C}$ é o nível de emprego dos que cumprem parcialmente a lei; $L_{C}$, dos que cumprem; $L_{N C}$, dos que descumprem, e $L_{w^{*}}$, no caso de ausência da lei no nível do salário de mercado $\left(w^{*}\right)$. Ou seja, firmas que cumprem parcialmente a legislação irão empregar a mesma quantidade de trabalhadores do que as que cumprem totalmente.

Squire e Narueput (1997) consideram também um modelo de equilíbrio parcial, mas com firmas heterogêneas e neutras ao risco, incorporando um parâmetro de produtividade $\left(\theta_{i}\right)$ que é

6 Se $m$ for o salário mínimo, $w$ o salário de mercado, então esta conclusão (ii) afirma formalmente que a firma decidirá não violar a lei se:

$w+\lambda k(m-w)>m$ 
crescente em relação ao tamanho das firmas. A probabilidade de ser inspecionado é crescente com a produtividade da firma $\left(\lambda^{\prime}\left(\theta_{i}\right)>0\right)$, ou seja, firmas maiores têm uma chance maior de serem investigadas. Além disso, os autores permitem à firma escolher entre cumprir, descumprir (pagar abaixo do salário mínimo) ou evitar legalmente (reduzindo contratações ou contratando trabalhadores de tempo parcial) a lei. Eles chegam às seguintes conclusões: (i) firmas com baixa produtividade descumprirão, de média produtividade cumprirão e de alta produtividade evitarão a lei; (ii) quanto maior $\lambda$ e/ou a multa fixa $(D)$, maior a proporção de firmas que cumprem e menor as que descumprem; (iii) quanto maior a precisão e compreensão da legislação (que aumenta os custos fixos de se evitar legalmente a lei), menor a proporção de firmas que evitam a lei e maior as que cumprem.

No entanto, em outro artigo recente, Yaniv (2004b) deriva também a curva de oferta dos trabalhadores. As curvas de demanda e oferta, em seu modelo, terão uma dependência direta do nível de efetividade da lei empregado pelas autoridades (ou seja, dependem de $\lambda k$ ). ${ }^{7}$ Assim, se o incentivo por parte do governo ( $\lambda k$ ) é insuficiente para induzir o cumprimento total da lei, a taxa de salário submínimo de equilíbrio cairá abaixo do salário de mercado (ver Figura 1). Portanto, se o objetivo da legislação do salário mínimo é aumentar o nível salarial, os agentes estarão piores em relação a antes de sua fixação. Além disso, ao contrário da evidência dos artigos acima citados, Yaniv (2006) considera a condição de equilíbrio de mercado, fechando o modelo em um contexto

7 Mais formalmente, o autor supõe que o lucro esperado da firma, caso não cumpra com a legislação, será:

$E(\pi)=p f\left(L^{d}\right)-[w+\lambda k(m-w)] L^{d}$,

em que, $p$ é o preço do produto, $f\left(\right.$.) a função de produção e $L^{d}$ as horas de trabalho demandadas. A utilidade do trabalhador é aditivamente separável nas horas ofertadas de trabalho e rendimentos, assumindo o formato: $U=-\varphi\left(L^{s}\right)+w L^{s}$, onde $\varphi\left(L^{s}\right)$ é a desutilidade do trabalho e $L^{s}$ horas ofertadas de trabalho. Assim, a sua utilidade esperada, dado que a firma não cumpre, será:

$E(U)=-\varphi\left(L^{s}\right)+[w+\lambda k(m-w)] L^{s}$.

Assim, obtêm-se as seguintes CPOs dos problemas da firma e do consumidor, respectivamente, para qualquer $w<m$ :

$p f^{\prime}\left(L^{d}\right)-[w+k \lambda(m-w)]=0$,

$-\varphi^{\prime}\left(L^{s}\right)-[w+k \lambda(m-w)]=0$,

em que $p, f^{\prime}\left(L^{d}\right), \varphi^{\prime}\left(L^{s}\right), L^{d}$ e $L^{s}$ são o preço do produto, as derivadas primeiras da função de produção e da desutilidade do trabalho, e as quantidades demandadas e ofertadas de trabalho, respectivamente. Aplicando o Teorema da Função Implícita nestas duas CPOs, obtemos:

$\frac{\partial L^{d}}{\partial(\lambda k)}=\frac{m-w}{p f^{\prime \prime}\left(L^{d}\right)}<0$

$\frac{\partial L^{s}}{\partial(\lambda k)}=\frac{m-w}{\varphi^{\prime \prime}\left(L^{s}\right)}<0$

em que, $f^{\prime \prime}\left(L^{d}\right)<0$ e $\varphi^{\prime \prime}\left(L^{s}\right)>0$, que implicam produtividade decrescente e desutilidade do trabalho crescente, respectivamente. Assim, conforme a Figura 1, um aumento da efetividade deslocará a curva de oferta para a direita e a da demanda para a esquerda. A mudança da inclinação pode ser observada diferenciando as duas CPOs em relação à $L$ e $w$ e depois em relação a $(\lambda k)$ :

$\frac{\partial w}{\partial L^{d} \partial(\lambda k)}=\frac{p f^{\prime \prime}\left(L^{d}\right)}{(1-\lambda k)^{2}}<0$,

$\frac{\partial w}{\partial L^{s} \partial(\lambda k)}=\frac{\varphi^{\prime \prime}\left(L^{s}\right)}{(1-\lambda k)^{2}}>0$.

Assim, um aumento em $(\lambda k)$ torna também as duas curvas mais inclinadas em termos absolutos. 
de equilíbrio geral, e chegando à conclusão de que o descumprimento da lei não terá efeito no nível de emprego.

Assim, é de consenso na maioria dos artigos que o grau de efetividade da lei dependerá da medida $\lambda k$. Logo, para as autoridades elevarem $\lambda$, terão de consumir recursos a fim de elevarem os esforços na fiscalização e processo penal das violações, embora isso possa incorrer em custos crescentes para a sociedade. Assim, pode ser compensatório elevar as multas $(k)$ a fim de incentivar o cumprimento das leis. Porém, esse mecanismo de incentivo também está restrito ao processo legislativo do Estado, que pode ser, em alguns países, lento demais.

Em suma, de acordo com os modelos teóricos revistos, podemos ter três situações. A primeira é se $\lambda k$ está bem próximo de um. Neste caso, as firmas cumprem o salário mínimo e isso pode gerar uma queda do nível de emprego (segundo os modelos de concorrência perfeita) ou não (segundo os modelos de monopsônio). A segunda situação é se $1>\lambda k>0$ (o grau de efetividade da lei é positivo, mas não suficientemente alto). Mesmo neste caso, pode haver descumprimento da legislação em dois aspectos: (i) evasão da lei (as firmas não pagam o salário mínimo) e (ii) redução ou impacto nulo do nível de emprego. Segundo o modelo de Yaniv (2006), se $\lambda k$ não for suficientemente alto, observaremos não apenas a evasão da lei, mas uma redução do nível de salário do mercado e um impacto nulo do nível de emprego (ver Figura 1 a seguir). E a terceira situação é se $\lambda k$ está bem próximo de zero. Segundo a Figura 1, as curvas de oferta e demanda praticamente não se deslocariam. Nesta situação, é como se não houvesse nenhuma alteração do nível salarial (permanecendo próximo do salário de mercado inicial $w_{0}$ ) e também não ocorreria nenhum impacto no nível de emprego. Portanto, avaliaremos os dois aspectos citados para se medir o quanto a lei é efetiva: o impacto sobre o nível salarial e sobre o nível de emprego.

8 Das CPOs mencionadas na nota anterior, podemos obter a função demanda e oferta, $L^{d}=L^{d}(\hat{w})$ e $L^{s}=L^{s}(\hat{w})$, onde $\hat{w}=w+\lambda k(m-w)$ que é a taxa de salário esperada (efetiva). Assim, o que importa para determinar o equilíbrio é $\hat{w}$, a variável que firmas e consumidores se depararão.

Assim, assumindo homogeneidade de $n$ firmas e $s$ empregados, a condição de ajustamento do mercado será:

$n L^{d}(\hat{w})=s L^{s}(\hat{w})$

ou seja, as curvas de oferta e demanda agregada se igualarão no nível de equilíbrio $\hat{w}$.

Se o governo conseguir impor algum nível positivo de efetividade da lei (ou seja, $0<\lambda k<1$ ), empregadores optarão por não cumprir a lei. A condição de equilíbrio acima mostra que esta medida $\lambda k$ de efetividade está contida em $\hat{w}$ tanto na oferta quanto na demanda. Portanto, qualquer mudança em $\lambda k$ afetará apenas a composição de $\hat{w}$, mas os efeitos serão compensados, visto que $\lambda k$ não aparece em nenhuma outra parte da condição acima de forma independente. Assim, as curvas de demanda e oferta se deslocam de tal forma que o nível de emprego não se altere, conforme Figura 1 . A taxa livre de mercado cai de $w_{0}$ para $w_{2}$, mas a taxa efetiva $\hat{w}$ permanece igual a $w_{0}$, ou seja, $w_{2}+\lambda k\left(m-w_{2}\right)=w_{0}$.

9 Deve-se ressaltar que a solução deste modelo é relativamente trivial. Note que o modelo do lado do consumidor pode ser visto da seguinte forma: o trabalhador joga uma loteria, na qual ele pode ganhar, em um estado da natureza, um salário maior que o salário mínimo (caso a firma seja punida), ou em outro estado da natureza, um salário abaixo do salário de mercado ( $w_{0}$ ). Como o trabalhador também é neutro ao risco em relação ao salário, o mesmo será indiferente entre permanecer empregado ou não e, assim, o nível de emprego não se altera. Assim, esta é uma política neutra em termos de utilidade esperada do trabalhador. Ou seja, os agentes não estarão piores em relação a antes da fixação da lei, pois não alterará sua utilidade esperada. 
Figura 1 - Descumprimento da lei e equilíbrio do mercado de trabalho

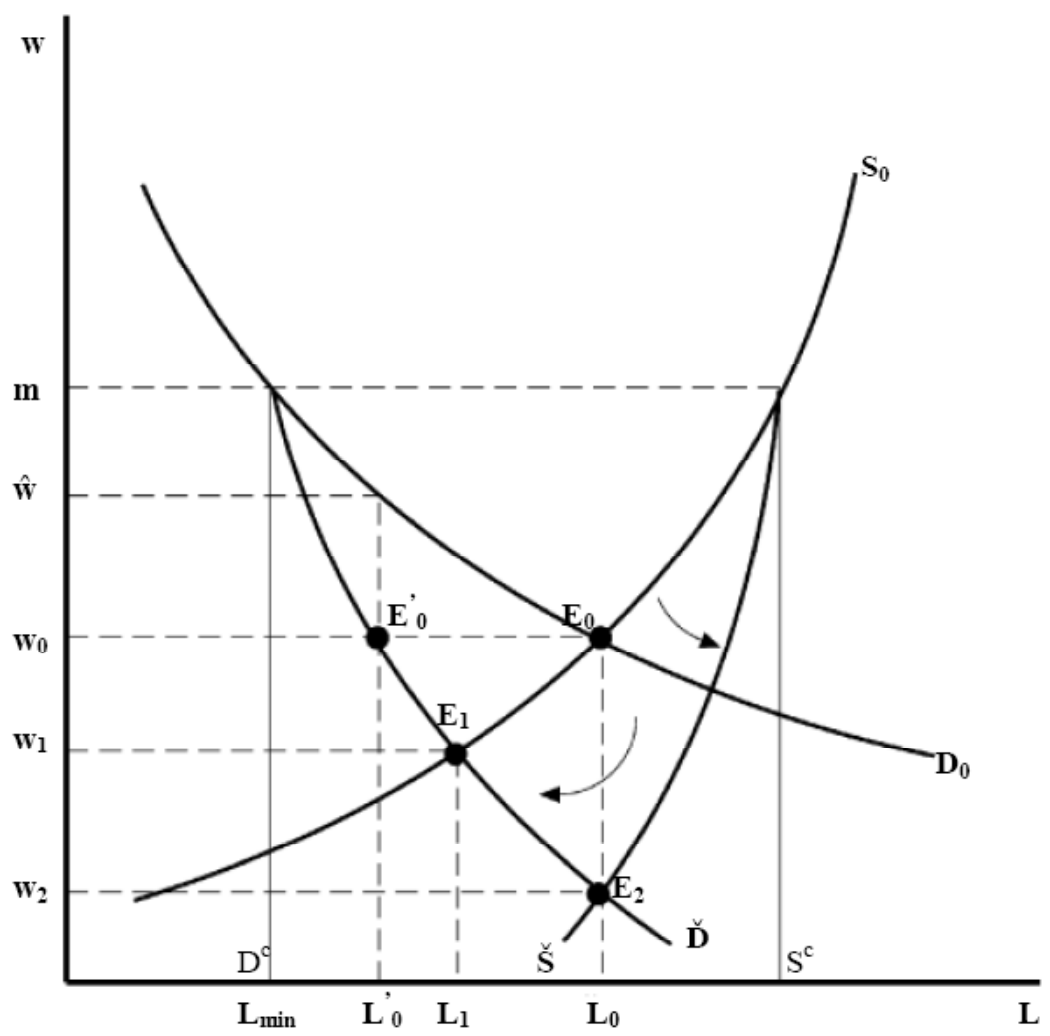

Fonte: Yaniv (2006).

\subsection{Considerações empíricas}

A grande maioria dos estudos parte da hipótese de cumprimento completo da lei para avaliar os impactos do salário mínimo sobre o nível de emprego e outras variáveis (CARD; KRUEGER, 1994; CARD, 1992a, 1992b; KATZ; KRUEGER, 1992; NEWMARK; WASCHER, 1992; BROWN et al., 1982; BROWN, 1988). No entanto, existem poucos artigos nesta área que testam ou avaliam o grau de violação da legislação do salário mínimo. A seguir, apresentamos a evidência empírica.

Evidência internacional - Um aspecto fundamental na investigação da efetividade da lei é a definição da medida de cumprimento da lei. AS adotam como medida de cumprimento da lei a proporção de trabalhadores que ganham exatamente o salário mínimo em relação aos que ganham igual ou abaixo do salário mínimo, após sua fixação. No entanto, segundo os autores, existem duas fontes de vieses: (i) a perda de emprego pelos trabalhadores do setor coberto pela lei implicaria cumprimento da lei, assim, esta medida de AS é viesada para baixo, e (ii) o fato mencionado que trabalhadores ganhariam exatamente o salário mínimo, mesmo na ausência da lei, viesa sua estimativa para cima. Os autores obtêm que, em 1973, 0.8\% somente dos trabalhadores que são cobertos pelo salário mínimo ganham abaixo deste piso, enquanto, para os descobertos, esta medida 
é de $13.7 \%$. Assim, segundo AS, essas taxas de descumprimento elevadas indicariam um paradoxo em relação ao modelo por eles especificado.

No entanto, Lott e Roberts (1995) questionam AS em relação ao fato destes considerarem a multa como uma fração do subpagamento, pois, caso fosse correta, não haveria incentivo para as potenciais firmas violadoras cumprirem a lei. Assim, para contrastar o resultado de AS, utilizam os mesmos dados, demonstrando que, apesar de se verificar penalidades baixas $(k)$, a probabilidade de ser punido um empregador infrator $(\lambda)$ é alta o suficiente, tal que o custo esperado $(\lambda k(m-w))$ está acima do benefício esperado (que é o subpagamento de salários) de violar a lei, o que torna o cumprimento racional. Os autores estimam os custos e penalidades em diversas dimensões, e mostram que não existe um paradoxo ao se obter taxas de cumprimento elevadas. O erro de AS é uma má interpretação dos documentos do governo, os quais acabam não incluindo todos os custos de se violar a lei.

Em um estudo de caso, Weil (2005) examina os determinantes do nível de cumprimento das leis do salário mínimo na indústria de vestuário dos EUA, pois historicamente tem empregado trabalhadores de baixo salário, existindo, portanto, uma maior propensão de as firmas desobedecerem à legislação. Utilizando microdados de 2000 para Los Angeles, o autor avalia o impacto de novos métodos de intervenção desenhados para melhorar a regulação deste mercado. O autor, estimando um modelo logit, conclui que: (i) a presença de monitoramento alto reduz a porcentagem de violadores em torno de $30 \%$, bem como a incidência (número de empregados que ganham menos que o salário mínimo por 100 empregados) em 17\%, e a severidade (salários abaixo do salário mínimo por empregado) das violações em $5 \%$, e (ii) enquanto as firmas que empregam trabalhadores de baixa qualificação tendem a ter uma maior probabilidade de violação, em torno de $26 \%$, em relação aos de média e alta qualificação.

Em outro estudo de caso, Dickens e Manning (2004) investigam o impacto da introdução do salário mínimo nacional na Inglaterra, em abril de 1999, sobre o nível de desigualdade, por meio de uma amostra de home cares. Neste estudo, os autores tomam o cuidado de avaliar o cumprimento da lei, obtendo uma taxa de obediência próxima de um e efeitos spillover muito pequenos. Stewart (2004) analisa também o efeito da introdução deste salário mínimo, obtendo um efeito nulo sobre o nível de emprego, utilizando um estimador de diferenças em diferenças, em um contexto de um quasi-experimento. $\mathrm{O}$ autor verifica que este efeito não é derivado de uma taxa de cumprimento da lei muito baixa, ao obter uma taxa entre $84 \%$ e $92 \%$ dos que ganham o salário mínimo em relação aos que ganham exatamente ou menos que o salário mínimo.

Em relação à evidência de países em desenvolvimento, em um estudo para Israel, Yaniv et al. (1998) utilizam como medida de obediência à lei o número de trabalhadores ganhando o salário mínimo, como uma porcentagem dos trabalhadores elegíveis pela lei (ou seja, que ganham o salário mínimo ou menos). Ele utiliza uma base de dados agrupados por setores econômicos. Os resultados obtidos por ele apontam que o cumprimento da lei aumenta: (i) ao longo do tempo (1988-1994); (ii) quanto menor a taxa de desemprego, pois aumenta o medo dos empregadores de serem denunciados por seus empregados, e (iii) quanto menor o gap entre o salário mínimo e o salário médio pago para trabalhadores de salário submínimo. Este último aspecto merece destaque. Um aumento neste gap gera, por um lado, um incentivo para a violação da lei, pois o ganho do subpagamento é maior que o custo esperado; mas, por outro lado, quanto maior este diferencial, maior a probabilidade de 
os empregados denunciarem o empregador, elevando os custos esperados e reduzindo, portanto, esta taxa de desobediência. Entretanto, a evidência empírica mostra que o primeiro efeito é maior do que o último. Além dessas estimativas, os autores avaliam uma estimação de dois estágios, pois existe também uma casualidade inversa entre o gap e o cumprimento da lei. Assim, estimam uma regressão auxiliar do gap como função do nível de cumprimento. O efeito teórico é que, para um aumento do cumprimento: (i) diminui a demanda dos empregadores por trabalhadores que ganham salários submínimos, e (ii) aumenta a oferta de trabalhadores desejando trabalhar a um salário submínimo (pois perderam seus empregos como um resultado da maior obediência das firmas). Este efeito conjunto gera um efeito positivo sobre o gap, embora os autores tenham obtido um efeito negativo. Uma explicação possível apontada é que um aumento no cumprimento aumenta as expectativas (e, portanto, as demandas) de trabalhadores ainda empregados que ganham um submínimo para receberem um salário maior.

Evidência brasileira - A evidência sobre o nível de cumprimento da legislação trabalhista brasileira, em especial a fixação do salário mínimo, é escassa no Brasil. Alguns dos poucos estudos que analisam diretamente a efetividade do salário mínimo são Neri et al. (1999, 2000).

Neri et al. (1999, 2000) estimam e identificam os principais determinantes do grau de efetividade do salário mínimo para os diversos Estados brasileiros, destacando-se a heterogeneidade de seus efeitos sobre os diferentes segmentos do mercado de trabalho. A medida de cumprimento à lei destes autores é a proporção de trabalhadores que recebem salários exatamente iguais ao salário mínimo em relação ao total. O problema desta medida é que ela não considera a perda de emprego dos trabalhadores binding, implicando um viés negativo, como apontado por AS. No entanto, o segundo viés (ii), apontado por AS, tende a ser pequeno em sua análise, pois o período de referência é o mês de setembro de 1996 (PNAD), cujo valor que vigorava era de $\mathrm{R} \$ 112$, ou seja, um valor quebrado. Eles obtêm uma proporção igual a $9 \%$ do total. Diferenciando em relação aos com e sem carteira, este valor é igual a $8 \%$ e 15\%, respectivamente. Em relação às regiões, Neri et al. (1999) mostram que o Norte/Centro-Oeste e Nordeste apresentam a maior porcentagem em relação ao total (12\% e $11 \%$, respectivamente). Isso reflete, como citado pelos autores, a grande heterogeneidade espacial do País. Além disso, este estudo avalia os determinantes da variação do grau de efetividade do salário mínimo entre os Estados brasileiros por meio de uma regressão por mínimos quadrados. Concluem que a efetividade do salário mínimo tende a ser menor nos Estados: (i) com menor PIB per capita; (ii) com maior nível educacional, e (iii) onde existe uma maior informalidade.

Outros estudos focam o impacto do salário mínimo na distribuição salarial, mensurando os chamados efeitos compressão e efeito spillover. Soares (2004), primeiramente utilizando dados da PNAD entre 1995 e 1999, nota que de $7 \%$ a $12 \%$ dos trabalhadores ganhavam exatamente um salário mínimo no universo do total de trabalhadores ocupados. Além disso, o autor estima as densidades do rendimento individual pelo método não-paramétrico de densidades de kernel. Assim, ele obtém que a efetividade do salário mínimo é maior entre mulheres, trabalhadores sem carteira, trabalhadores que vivem no Nordeste, cônjuges e filhos, pessoas com pouca instrução (0-3 séries de escola), jovens, trabalhadores no setor agrícola, trabalhadores domésticos, negros e pessoas nos primeiros três décimos da renda domiciliar per capita. Em seguida, utilizando dados da PME de 1995 a 1997, estima regressões em vários pontos ao longo da distribuição, encontrando efeitos significativos do salário mínimo sobre a parte inferior da distribuição salarial, tanto para aqueles que recebem abaixo (obtém elasticidades médias do período de 0.61), igual (elasticidades de 0.72) e logo 
acima do salário mínimo (elasticidades de 0.56), mas encontrando efeitos pequenos no topo da distribuição (elasticidades de 0.2). Assim, ele obtém evidência para os efeitos compressão e spillover.

Lemos (2003), utilizando dados individuais PME de 1982 a 2000 e técnicas de dados em painel, mostra que um aumento do salário mínimo exerce efeito compressão forte sobre a distribuição salarial. De modo geral, a autora encontra efeitos fortes: elasticidade de 0.56 para centésimo 5 da distribuição, em torno de 0.6 para indivíduos nos centésimos 10 a 20, e decaindo até 0.1 no centésimo 95.

Corseuil e Carneiro (2001) utilizam dados da PME de 1995 até 1999 da metade da década de 1990 e também obtêm efeitos compressão elevados, analisando tanto o setor formal como todos os setores conjuntamente. E obtêm efeitos spillover moderados, os quais os autores justificam devido, provavelmente, ao fim da política de indexação dos salários pré-Plano Real.

Fajnzylber (2001), utilizando dados da PME de 1982 até 1997, também estima os efeitos de aumentos no salário mínimo em diferentes pontos da distribuição de rendimentos. Ele computa as elasticidades da renda dos agentes em relação ao salário mínimo no ano do aumento e no ano defasado, controlando diversas variáveis. Ele obtém elasticidades em relação ao salário mínimo elevadas, próximas de um, para indivíduos com rendimentos próximos ao salário mínimo, tanto para o setor formal, informal e conta própria. Para pessoas com renda localizada no topo da distribuição, as elasticidades são menores, variando de 0.2 a 0.4 . Assim, obtém efeitos spillover considerados ao longo de toda a distribuição. Neumark et al. (2006), utilizando também dados da PME de 1996 até 2001, estimam efeitos do salário mínimo. Para os rendimentos individuais, eles obtêm efeitos compressão para os trabalhadores de menor nível de renda, mas não obtêm efeitos spillover para trabalhadores de renda elevada. Os autores também estimam o efeito do salário mínimo nos menores decis da distribuição da renda familiar e não encontram evidências de efeitos spillover nos quantis menores da distribuição. Esta diferença observada entre estes dois trabalhos surge, segundo Lemos (2007), devido ao fato que Fajnzylber (2001) utiliza períodos de alta inflação, para os quais os efeitos spillover tendem a ser maiores, e Neumark et al. (2006) utilizaram somente períodos mais recentes de baixa inflação.

Assim, estes estudos encontram uma forte evidência de efetividade da lei do salário mínimo, tanto em termos de efeito compressão e algum efeito spillover. Tais evidências, aqui apontadas, justificam a análise dos pisos, pois, caso contrário, uma efetividade baixa ou nula do salário mínimo necessariamente implicaria uma efetividade baixa ou nula dos pisos estaduais.

\section{LEgislação}

A lei complementar $n^{\circ} 103$, que entrou em vigor em 17 de julho de 2000, autorizou os Estados e o Distrito Federal a instituirem o piso salarial a que se refere o inciso $\mathrm{V}$ do art. $7^{\circ}$ da Constituição Federal para os empregados que não tenham piso salarial definido em lei federal, convenção ou acordo coletivo de trabalho. Deve-se destacar que este piso não pode ser estipulado no segundo semestre do ano em que houver eleição para governador dos Estados e do Distrito Federal e de deputados estaduais e distritais, e também em relação à remuneração de servidores públicos municipais. 
A Tabela 1 resume os valores dos salários mínimos federais (salário mínimo) e dos pisos estaduais do RJ e RS, medidos em reais. As datas com o mês e ano abreviados, apresentados na tabela, se referem ao período que entraram em vigor as leis do salário mínimo e dos pisos. Ressalta-se aqui que nos referiremos a esses grupos como I, II, III para o RJ, bem como I, II, III, IV para o RS. Estes grupos constituem-se basicamente de ocupações de baixa qualificação. No Apêndice 1 estão definidos os grupos profissionais para cada Estado.

Tabela 1 - Valores de salário mínimo federal e pisos salariais estaduais

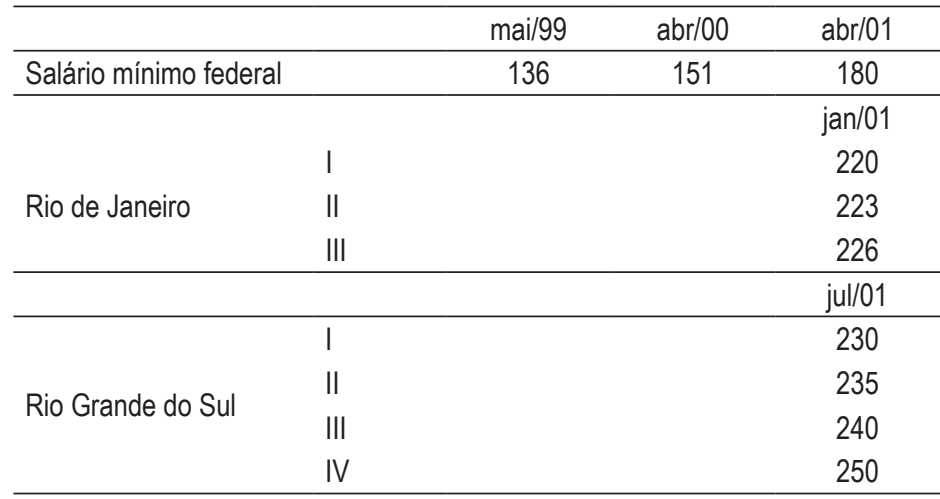

Fonte: Elaboração própria a partir da legislação.

Nota: Os grupos I, II, III do RJ e I, II, III e IV do RS estão definidos no Apêndice 1. Estes grupos tratamse das ocupações definidas pelas respectivas legislações estaduais e que estão aptos a receber o piso salarial determinado. As datas referem-se ao mês e ano nos quais o salário mínimo e os pisos salariais estaduais foram fixados.

Ressaltamos que a lei estadual do RJ e RS não define uma multa para o caso de sua violação. No entanto, caso haja atraso de pagamento de salários por parte da firma, esta estará infringindo os artigos 4 e 459 da CLT, cuja multa será de $\mathrm{R} \$ 170^{10}$ por empregado prejudicado, que é dobrada sempre em caso de reincidência. Assim, os empregadores que descumprissem a lei dos pisos estaduais estariam sujeitos a esta multa. Além disso, a firma, ao desobedecer à lei, estará descumprindo o artigo 444 da CLT, o qual afirma que os contratos de trabalho não podem violar as decisões das autoridades competentes e no qual a fiscalização se baseia para monitorar o pagamento devido dos salários.

Outro aspecto a ser destacado é que os trabalhadores podem denunciar anonimamente os empregadores na Delegacia Regional do Trabalho do Estado onde residem. Assim, além da fiscalização independente deste órgão, os fiscais irão averiguar e punir a firma em caso de violação da lei, se houver denúncia. Portanto, esta fiscalização, ao averiguar o não pagamento devido dos salários, poderá exigir apenas o pagamento dos valores atrasados ou impor uma multa às firmas. Geralmente, o prazo para este pagamento varia de dois a oito dias, podendo ser renovado pelo fiscal, em caso de dificuldade da firma. Caso o empregador, após todas as autuações e multas da fiscalização, não cumprir com a legislação, é movido um processo pelo Ministério do Trabalho, no qual a firma

10 A multa é definida em 160 unidades da UFIR, cujo valor atual está em R $\$ 1.0641$. 
violadora estará sujeita a uma indenização de valor muito superior às multas e atrasos salariais não pagos. ${ }^{11}$

Além destas penalidades impostas diretamente pelo governo, os empregadores estão sujeitos a processos penais movidos diretamente pelos empregados, de acordo com o artigo 483 da CLT, podendo pagar indenizações muito superiores ao gap não pago.

Destacamos também que, mesmo na ausência de multas, os empregadores poderiam cumprir a legislação de acordo com os modelos de salário-eficiência, segundo o qual eles pagariam um salário acima do salário de equilíbrio do mercado. ${ }^{12}$ A seguir, descrevemos brevemente a base de dados e a amostra utilizada.

\section{BREVE DESCRIÇÃO DOS DADOS}

Utilizamos dados de painel da PME, que cobre as regiões metropolitanas do Rio de Janeiro/ Porto Alegre e São Paulo (SP) para os anos de 2000 e 2001. A PME é um painel rotativo, cujo principal objetivo é fazer o acompanhamento do mercado de trabalho nas áreas metropolitanas do País. As entrevistas são realizadas por quatro meses consecutivos, depois se faz uma pausa de oito meses e então volta-se a entrevistar este indivíduo por mais quatro meses consecutivos, abrangendo, assim, os mesmos meses nos dois anos pesquisados.

Além disso, a pesquisa é realizada com os trabalhadores, os quais reportam o salário que recebem de seus empregadores, não existindo, assim, incentivo para os empregados subestimarem uma eventual violação da legislação por parte das firmas.

As análises foram feitas apenas para as ocupações afetadas pela lei, excluindo, portanto, funcionários públicos, ${ }^{13}$ conta própria, empregadores, trabalhadores na produção para o próprio consumo e na construção para o próprio uso, não remunerados e sem declaração.

\section{AVAliaÇÃo DA EFETIVIDADE DA LEI}

Nesta seção avaliamos a efetividade da lei. Para isto, analisamos primeiramente algumas estatísticas descritivas e depois os resultados das regressões quantílicas.

11 Estas informações foram obtidas na Delegacia Regional do Trabalho do RJ. Estes aspectos relacionados às penalidades e fiscalização são válidos tanto para o RJ como para o RS.

12 O modelo de salário-eficiência é simplesmente uma aplicação do modelo do principal agente da teoria de contratos. Neste modelo, existe um problema de risco moral, onde o empregador (principal) não observa o esforço do trabalhador (agente). Assim, dada a hipótese de que os custos de monitoramento do esforço são muito elevados, uma "segunda melhor" solução (second best solution) do modelo seria que os empregadores devem pagar um salário maior que o salário de equilíbrio do mercado (que seria uma "primeira melhor" solução, caso observassem o esforço do agente [first best solution]). Este salário maior geraria um incentivo para que os trabalhadores se esforçassem mais no emprego.

13 Apesar de a lei excluir apenas funcionários públicos municipais, optamos por retirar todos os funcionários públicos, visto que os mesmos têm regimes salariais diferentes dos demais trabalhadores. 


\subsection{Estratégia empírica}

A estratégia de identificação da efetividade da lei consiste em verificar se houve uma alteração do gap entre o salário pago ao trabalhador e o salário mínimo, maior no grupo de tratamento em relação ao grupo de controle, de um ano para outro. Em função disso, foram adotados Estados que tivessem distribuições salariais semelhantes antes de a lei ser implementada. No cenário hipotético de a lei ser efetiva, esperar-se-ia um aumento do diferencial salarial maior nos Estados que a adotaram, gerando novos pontos de pressão nos pisos definidos. Entretanto, deve-se notar que a lógica inversa não é necessariamente válida. Caso haja um efeito positivo no diferencial salarial dos Estados adotantes em relação aos outros, a lei pode ser não efetiva, pois os rendimentos nestes Estados poderiam se elevar mais do que nos outros por força de algum outro fator exógeno. Ou ainda, simplesmente porque o rendimento médio dos Estados aderentes à lei pode, por razões históricas, ser maior do que nos Estados de comparação. Por isso, é importante se adotar Estados de comparação com distribuições salariais próximas.

Grupo de controle - O que procuramos fazer foi tomar um conjunto de Estados que pudéssemos comparar, utilizando o critério de distribuições salariais similares. Assim, calculamos a distância de informação de Kullback-Leibler, definida como:

$$
I(\hat{f}, \hat{g})=\int[\hat{f}(x)-\hat{g}(x)] \ln \left[\frac{\hat{f}(x)}{\hat{g}(x)}\right] d x,
$$

em que $\hat{f}(x)=\frac{1}{n h} \sum_{i=1}^{n} K\left(\frac{x_{i}-x}{h}\right)$ é o estimador de densidade de kernel (núcleo) dos salários. ${ }^{14}$ Utilizamos a "regra de bolso" de Silverman (1986), para a escolha da janela $h$ :

$$
h=\frac{0.9 \min \left(\sigma_{x}, R_{x} / 1.34\right)}{n^{1 / 5}},
$$

em que $\sigma_{x}$ é o desvio padrão amostral e $R_{x}$ é a razão interquantílica. Assim, estimamos $f(x)$ para $\mathrm{RJ} / \mathrm{RS}$ e $g(x)$ para diversos Estados, para as ocupações definidas nas leis estaduais, e minimizamos $I(f, \hat{g})$, a fim de obter Estados com distribuições bem próximas. Da Tabela 2, notamos que SP é o Estado que mais se aproxima do RJ e RS em termos de rendimentos, apresentando uma distância de Kullback-Leibler razoavelmente pequena em todos os meses anteriores à vigência da lei. Assim, como a renda média de SP é maior do que a do RJ e RS (ver Tabela 3, a seguir), caso a lei seja efetiva, esta distância deve se reduzir. Essa possível evidência será mais precisamente analisada na estimação das regressões quantílicas quando controlarmos para diversos fatores e analisarmos os coeficientes dos quantis binding.

14 O termo $K\left(\frac{x_{i}-x}{h}\right)$ é o kernel e adotamos um kernel gaussiano. Como é de conhecimento comum da literatura não-paramétrica (SILVERMAN, 1986), existe pouca diferença de eficiência (com base na norma do erro quadrático médio integrado) entre os diferentes kernels. 
Tabela 2 - Distâncias de informação de Kullback-Leibler ${ }^{15}$

\begin{tabular}{|c|c|c|c|c|c|c|c|c|c|}
\hline \multicolumn{5}{|c|}{ Ocupações do Rio de Janeiro } & \multicolumn{5}{|c|}{ Ocupações do Rio Grande do Sul } \\
\hline data & $\begin{array}{c}\text { São } \\
\text { Paulo }\end{array}$ & Pernambuco & Bahia & $\begin{array}{l}\text { Minas } \\
\text { Gerais }\end{array}$ & data & $\begin{array}{l}\text { São } \\
\text { Paulo }\end{array}$ & Pernambuco & Bahia & $\begin{array}{l}\text { Minas } \\
\text { Gerais }\end{array}$ \\
\hline janeiro/2000 & 0.09 & 0.43 & 0.31 & 0.06 & janeiro/2001 & 0.08 & 0.41 & 0.33 & 0.14 \\
\hline fevereiro/2000 & 0.10 & 0.37 & 0.37 & 0.10 & fevereiro/2001 & 0.04 & 0.52 & 0.45 & 0.28 \\
\hline março/2000 & 0.08 & 0.40 & 0.42 & 0.10 & março/2001 & 0.05 & 0.43 & 0.41 & 0.23 \\
\hline abril/2000 & 0.06 & 0.41 & 0.38 & 0.12 & abril/2001 & 0.05 & 0.44 & 0.41 & 0.24 \\
\hline maio/2000 & 0.05 & 0.56 & 0.42 & 0.15 & maio/2001 & 0.03 & 0.34 & 0.25 & 0.22 \\
\hline junho/2000 & 0.06 & 0.46 & 0.41 & 0.14 & junho/2001 & 0.06 & 0.46 & 0.32 & 0.20 \\
\hline julho/2000 & 0.08 & 0.56 & 0.39 & 0.11 & julho/2001 & 0.06 & 0.51 & 0.38 & 0.22 \\
\hline Média & 0.07 & 0.46 & 0.39 & 0.11 & Média & 0.05 & 0.44 & 0.36 & 0.22 \\
\hline
\end{tabular}

Fonte: Elaboração própria a partir dos dados da PME.

Nota: As áreas sombreadas referem-se às distâncias menores ou iguais a 0.1.

Análise descritiva da amostra - A Tabela 3 apresenta as características da amostra que será considerada para dois dos grupos de períodos que serão analisados (sempre um mês pré e outro pós-lei), para o grupo de tratamento e o grupo de controle. Notamos que: (i) o salário real de SP é sempre superior ao do RJ/RS; (ii) as mulheres têm uma menor participação nas ocupações definidas na legislação, mas tal porcentagem se elevou no mês pós-lei; (iii) a idade média está em torno de 33 a 35 anos; (iv) o nível de escolaridade é sempre maior em SP, e (v) mais de $70 \%$ destes trabalhadores estão no setor formal.

Tabela 3 - Valores médios das variáveis da amostra por períodos de comparação

\begin{tabular}{|c|c|c|c|c|c|c|c|c|}
\hline \multirow{3}{*}{ Variáveis } & \multicolumn{4}{|c|}{ RJ } & \multicolumn{4}{|c|}{ SP } \\
\hline & \multicolumn{2}{|c|}{ mar00/mar01 } & \multicolumn{2}{|c|}{ abr00/abr01 } & \multicolumn{2}{|c|}{ mar00/mar01 } & \multicolumn{2}{|c|}{ abr00/abr01 } \\
\hline & $\mathrm{mar} / 00$ & mar/01 & $\mathrm{abr} / 00$ & $\mathrm{abr} / 01$ & mar/00 & mar/01 & $\mathrm{abr} / 00$ & $\mathrm{abr} / 01$ \\
\hline Renda & 634.67 & 625.31 & 656.02 & 673.28 & 834.52 & 873.71 & 827.78 & 838.95 \\
\hline Sexo & 0.39 & 0.39 & 0.40 & 0.41 & 0.49 & 0.50 & 0.47 & 0.47 \\
\hline Idade & 35.87 & 36.84 & 35.62 & 36.59 & 34.41 & 35.38 & 33.38 & 34.35 \\
\hline Educação & 7.23 & 7.27 & 7.59 & 7.65 & 8.06 & 8.13 & 7.85 & 7.91 \\
\hline Carteira & 0.75 & 0.78 & 0.77 & 0.80 & 0.76 & 0.77 & 0.76 & 0.80 \\
\hline \multirow[t]{2}{*}{$\mathrm{N}^{0}$ Obs. } & 527 & 527 & 519 & 519 & 819 & 819 & 791 & 791 \\
\hline & \multicolumn{4}{|c|}{$\mathrm{RS}$} & \multicolumn{4}{|c|}{$\mathrm{SP}$} \\
\hline \multirow[t]{2}{*}{ Variáveis } & \multicolumn{2}{|c|}{ jun01/ago01 } & \multicolumn{2}{|c|}{ jul01/set01 } & \multicolumn{2}{|c|}{ jun01/ago01 } & \multicolumn{2}{|c|}{ jul01/set01 } \\
\hline & jun/01 & ago/01 & jul/01 & set/01 & jun/01 & ago/01 & jul/01 & set/01 \\
\hline Renda & 736.21 & 720.88 & 673.95 & 673.94 & 1004.16 & 1003.38 & 891.53 & 901.15 \\
\hline Sexo & 0.46 & 0.46 & 0.45 & 0.45 & 0.43 & 0.43 & 0.42 & 0.42 \\
\hline Idade & 34.90 & 35.07 & 34.72 & 34.89 & 33.78 & 33.95 & 33.99 & 34.14 \\
\hline Educação & 7.50 & 7.50 & 7.25 & 7.25 & 8.06 & 8.07 & 7.88 & 7.89 \\
\hline Carteira & 0.82 & 0.82 & 0.81 & 0.83 & 0.72 & 0.73 & 0.72 & 0.72 \\
\hline $\mathrm{N}^{0}$ Obs. & 925 & 925 & 983 & 983 & 1096 & 1096 & 1201 & 1201 \\
\hline
\end{tabular}

Fonte: Elaboração própria a partir dos dados da PME.

Nota: Renda $=$ renda deflacionada do trabalho, Sexo $=0$ para homem e 1 para mulher, Educação $=$ anos de estudo, Carteira $=0$ se não tem carteira assinada e 1 se tem, $\mathrm{N}^{\circ}$ Obs. = número de observações.

15 Estimamos as densidades para um grid de 1 a 1000, espaçados em intervalos de 1. 


\subsection{Análise descritiva da efetividade da lei}

Destacamos agora a importância da participação das ocupações definidas na lei no universo de ocupados. Observamos que em torno de $12 \%$ a $27 \%$ do total de trabalhadores no RJ e RS, respectivamente, pertencem a alguma das profissões definidas nas legislações estaduais. Assim, o potencial impacto na lei tenderia a afetar significativamente a distribuição salarial.

Analisamos a efetividade da lei, a partir da Tabela 4, a seguir, que resume a distribuição dos rendimentos para todas as ocupações em todos os meses em faixas de valores. Se a lei fosse efetiva, esperar-se-ia a criação de novos pontos de pressão nos pisos recém-definidos, porém, quando consideramos a categoria I das ocupações da lei do RJ, composta de empregados domésticos, de limpeza, turismo, comerciários, entre outros, notamos uma concentração de massa salarial, igual ao piso, de 1.19\%, em março/2000, passando a 1.5\%, em março/2001, logo após a promulgação da lei no Estado; ou seja, um aumento muito pequeno. No entanto, observamos uma queda na efetividade do salário mínimo, o que pode indicar algum grau de efetividade dos pisos. Para o RS, houve uma maior concentração de massa nos pisos com a promulgação da lei, passando de $0.87 \%$ em junho/2001 para 2.8\% em agosto/2001, e, aliado a isso, houve uma redução da efetividade do salário mínimo. Apesar de se observar alguma concentração de massa no ponto de acumulação do salário mínimo federal, esta é uma condição necessária, mas não suficiente, para que a lei não seja efetiva. Muitos indivíduos que recebiam entre o salário mínimo e o piso poderiam ter sido afetados pela lei ou, ainda, os indivíduos que já recebiam um pouco acima dos pisos estaduais de salário poderiam ter sofrido algum reajuste devido à lei. Este impacto é o chamado efeito spillover (CARD; KRUEGER, 1995). Para as distribuições dos rendimentos das outras classes e meses, observamos um nível grande de descumprimento.

Em relação a $\mathrm{SP}{ }^{16}$ observaram-se freqüências relativamente menores nos pisos estaduais em relação ao grupo de tratamento, bem como, na maioria dos casos, uma porcentagem também bem menor no salário mínimo. As porcentagens um pouco mais altas, em alguns casos, em SP, se devem muito mais aos números redondos dos pisos, mas, mesmo nestes casos, apresentando uma freqüência menor do que RJ/RS; para rendimentos entre o salário mínimo e o piso dos dois Estados, apresentam também porcentuais relativamente menores. Somente para rendimentos acima do piso, a freqüência de rendimentos é maior do que RJ/RS.

16 As freqüências por pisos para SP foram omitidas, mas pode ser requisitadas aos autores. 
Tabela 4 - Freqüência dos rendimentos com pontos críticos no salário mínimo e nos pisos (em \%)

\begin{tabular}{|c|c|c|c|c|c|c|c|c|c|c|c|}
\hline RJ & $\mathrm{mar} / 00$ & abr/00 & $\mathrm{jan} / 01$ & fev/01 & $\mathrm{mar} / 01$ & abr/01 & RS & jun/01 & jul/01 & ago/01 & set/01 \\
\hline SM vigente & 136 & 136 & 151 & 151 & 151 & 151 & SM vigente & 180 & 180 & 180 & 180 \\
\hline I & & \multicolumn{4}{|c|}{ piso $=220$} & \multicolumn{2}{|r|}{ I } & \multicolumn{4}{|c|}{ piso $=230$} \\
\hline$w<s m$ & 5.48 & 3.55 & 5.82 & 5.16 & 4.95 & 5.24 & $w<s m$ & 10.76 & 10.82 & 11.49 & 9.91 \\
\hline$w=s m$ & 5.72 & 4.85 & 4.47 & 5.87 & 4.03 & 3.53 & $\mathrm{w}=\mathrm{sm}$ & 14.73 & 13.38 & 10.66 & 10.41 \\
\hline $\mathrm{sm}<\mathrm{w}<$ piso & 16.57 & 17.38 & 11.1 & 12.79 & 11.52 & 12.64 & sm $<$ w $<$ piso & 12.98 & 10.63 & 9.73 & 11.91 \\
\hline w=piso & 1.19 & 2.13 & 2.3 & 1.76 & 1.5 & 1.71 & $w=$ piso & 0.87 & 1.33 & 2.80 & 2.10 \\
\hline$w>$ piso & 71.04 & 72.1 & 76.32 & 74.41 & 78 & 76.88 & $w>$ piso & 60.66 & 63.85 & 65.32 & 65.67 \\
\hline Total & 100 & 100 & 100 & 100 & 100 & 100 & Total & 100 & 100 & 100 & 100 \\
\hline II & & \multicolumn{4}{|c|}{ piso $=223$} & & II & \multicolumn{4}{|c|}{ piso $=235$} \\
\hline$w<s m$ & 7 & 7.23 & 6.18 & 6.96 & 8.24 & 8.51 & $w<s m$ & 3.02 & 3.47 & 1.73 & 1.83 \\
\hline$w=s m$ & 2.38 & 3.1 & 0.67 & 1.39 & 1.65 & 1.74 & $w=s m$ & 4.54 & 6.02 & 3.7 & 5.48 \\
\hline sm $<$ w $<$ piso & 19.08 & 17.56 & 12.35 & 13.04 & 13.51 & 15.1 & sm $<w<$ piso & 11.02 & 12.73 & 7.65 & 10.96 \\
\hline W=piso & 0 & 0 & 0 & 0 & 0 & 0 & $w=p i s o$ & 0 & 0.23 & 0.25 & 0 \\
\hline$w>$ piso & 71.54 & 72.12 & 80.8 & 78.61 & 76.61 & 74.65 & $w>$ piso & 81.43 & 77.55 & 86.67 & 81.74 \\
\hline Total & 100 & 100 & 100 & 100 & 100 & 100 & Total & 100 & 100 & 100 & 100 \\
\hline III & & \multicolumn{4}{|c|}{ piso $=226$} & & III & \multicolumn{4}{|c|}{ piso $=240$} \\
\hline$w<s m$ & 3.06 & 3.85 & 6.22 & 1.78 & 2.76 & 2.96 & $w<s m$ & 4.46 & 5.56 & 3.84 & 4.15 \\
\hline$w=s m$ & 1.53 & 0.55 & 0.52 & 1.78 & 0.55 & 0.59 & $w=s m$ & 4.19 & 4.37 & 3.75 & 3.26 \\
\hline $\mathrm{sm}<\mathrm{w}<$ piso & 7.65 & 5.49 & 5.18 & 4.14 & 7.73 & 9.47 & sm $<$ w $<$ piso & 7.64 & 6.92 & 7.40 & 6.43 \\
\hline$w=$ piso & 0 & 0 & 0 & 0 & 0 & 0 & $w=p i s o$ & 0.55 & 1.09 & 0.67 & 0.69 \\
\hline$w>$ piso & 87.76 & 90.11 & 88.08 & 92.31 & 88.95 & 86.98 & $w>$ piso & 83.17 & 82.06 & 84.34 & 85.46 \\
\hline Total & 100 & 100 & 100 & 100 & 100 & 100 & Total & 100 & 100 & 100 & 100 \\
\hline- & - & - & - & - & - & - & IV & \multicolumn{4}{|c|}{ piso $=250$} \\
\hline - & - & - & - & - & - & - & $w<s m$ & 2.59 & 2.68 & 1.98 & 1.86 \\
\hline - & - & - & - & - & - & - & $\mathrm{w}=\mathrm{sm}$ & 5.48 & 3.94 & 3.68 & 3.44 \\
\hline - & - & - & - & - & - & - & $\mathrm{sm}<\mathrm{w}<$ piso & 7.49 & 7.61 & 7.22 & 8.02 \\
\hline - & - & - & - & - & - & - & $\mathrm{w}=$ piso & 4.32 & 2.96 & 4.11 & 4.15 \\
\hline - & - & - & - & - & - & - & $w>$ piso & 80.12 & 82.82 & 83 & 82.52 \\
\hline- & - & - & - & - & - & - & Total & 100 & 100 & 100 & 100 \\
\hline
\end{tabular}

Fonte: Elaboração Própria a partir dos dados da PME e da legislação.

Nota: $\mathrm{SM}=$ salário mínimo, $\mathrm{w}=$ rendimento do trabalho principal, piso $=$ valor do piso estadual das categorias I, II, III do RJ e I, II, III e IV do RS. A composição destes grupos está detalhada no Apêndice 1. Cada porcentagem refere-se a cada faixa para um dado mês. Então, por exemplo, para as ocupações do grupo I do RJ em março de 2000 (segunda coluna), $5.48 \%$ dos seus rendimentos estão abaixo do salário mínimo, enquanto 5.72\% recebem exatamente o salário mínimo e assim sucessivamente, totalizando $100 \%$ para um dado mês, grupo e Estado.

\subsection{Regressões quantílicas para dados longitudinais}

As regressões foram estimadas separadamente para cada Estado adotante da lei (RJ e RS) e incluindo todos os grupos ocupacionais definidos nas leis destes Estados. Além disso, para este modelo, deflacionamos o rendimento dos agentes (pelo INPC, a preços de novembro de 2005), bem como o salário mínimo, com o intuito de isolar o efeito da inflação sobre algum possível ganho salarial. Por exemplo, estimou-se o efeito do gap entre o salário pago pelo empregador e o salário mínimo para o RJ em relação a SP, incluindo as ocupações dos três grupos profissionais 
definidos na lei de 2001 do RJ. A escolha do gap como variável dependente se deve a dois motivos: (i) se analisássemos apenas a variação do nível salarial, poderia ocorrer que, por exemplo, RJ tivesse uma maior variação que SP, mas devido ao aumento do salário mínimo, que seria mais efetivo no primeiro Estado do que no segundo, e não devido à mudança na legislação, e (ii) espera-se que o aumento considerável dos pisos perante o salário mínimo tenha algum impacto na variação do gap, caso a lei apresente algum grau de efetividade.

Ressaltamos que as estimativas foram realizadas para um conjunto de datas base e final, ao qual fazemos referência no título de cada gráfico. Como as leis estaduais diferem em termos de data de implantação, os conjuntos de datas base e final são específicos para cada Estado. A escolha das datas foi realizada com o intuito de isolar os efeitos do piso salarial estadual do aumento do salário mínimo nacional que ocorreu em maio de 2000 e maio de 2001.

Em relação à metodologia adotada, ressaltamos que regressões da média condicional poderiam não captar algum possível grau de efetividade da lei para os quantis entre o salário mínimo e o piso salarial estadual ou, ainda, para pessoas que ganhem exatamente ou logo acima dos novos pisos instituídos. Ressaltamos também outra vantagem da regressão quantílica: ela é robusta a outliers, sendo, portanto, menos sensível à presença de valores discrepantes, em relação à regressão de média condicional. Assim, dado este aspecto e as características dinâmicas da base, adotamos uma abordagem de regressão quantílica para dados longitudinais, segundo Koenker (2004), o qual propôs um modelo que incorpora efeitos fixos. Assim, seja o seguinte modelo para funções quantílicas condicionais:

$$
\begin{aligned}
& Q_{y_{i t}}\left(\tau \mid x_{i t}\right)=\alpha_{i}+\beta_{1}(\tau) \operatorname{sexo}_{i t}+\beta_{2}(\tau) \text { carteira }_{i t}+\beta_{3}(\tau) \text { idade }_{i t}+\beta_{4}(\tau) e d u c_{i t}+ \\
& \beta_{5}(\tau) \text { trat }_{i t}+\beta_{6}(\tau) \text { dmes }_{t}+\beta_{7}(\tau) \text { trat }_{i t} * \text { dmes }_{t}, i=1, \ldots, n, t=1, \ldots T
\end{aligned}
$$

em que $\tau$ é um quantil, $y_{i t}$ é a diferença entre o salário do indivíduo $i$ no período $t$ e o salário mínimo do período $t, \alpha_{i}$ é o efeito fixo. Os regressores considerados são: variáveis dummies para sexo e carteira assinada (carteira), idade, educação (educ), e variáveis dummies se o indivíduo pertence ao grupo de tratamento (trat, valor 1 se pertence ao grupo de tratamento e 0 caso contrário), para o mês pós-lei (dmes, valor 1 para o mês pós-lei e 0 para o mês pré-lei) e uma variável dummy de interação entre estas duas últimas $\left(\right.$ trat $^{*}$ dmes $\left._{t}\right)$.

Esta última variável representa um estimador análogo ao de diferenças em diferenças. Ressalta-se que a variável trat capta se os agentes pertencem, no período inicial, ao seu grupo ocupacional e, no período seguinte, consideramos que eles podem ter permanecido dentro de seu grupo ocupacional ou migraram para outro grupo ocupacional, mas este especificado na lei. $\mathrm{O}$ objetivo aqui é diferente da seção posterior sobre avaliação do nível de emprego, visto que queremos medir o grau de evasão da lei por parte dos empregadores, mediante a análise de alteração dos salários dos trabalhadores dentro das ocupações afetadas pela lei.

Ressaltamos que o termo $\alpha_{i}$ é o efeito fixo que capta outras características do indivíduo que não são observáveis, mas que certamente têm impacto no seu nível salarial. Como exemplo destas características, podemos citar as habilidades cognitivas e não-cognitivas. Além disso, $\alpha_{i}$ é independente dos quantis, ou seja, $\alpha_{i}(\tau) \equiv \alpha_{i}$. Esta hipótese é adotada por Koenker (2004), pois o número 
de observações para cada indivíduo, $T$, é muito pequeno (no nosso caso, $T=2$ ). Assim, não é viável estimar a mudança distribucional de $\alpha$ para cada indivíduo que seja dependente do quantil $\tau$.

Assim, para inferir o modelo (2) para diversos quantis simultaneamente, consideramos os estimadores que resolvem o seguinte problema penalizado (KOENKER, 2004):

$$
\min _{(\alpha, \beta)} \sum_{k=1}^{q} \sum_{t=1}^{T} \sum_{i=1}^{n} w_{k} \rho_{\tau_{k}}\left(y_{i t}-\alpha_{i}-x_{i t}^{\prime} \beta\left(\tau_{k}\right)\right)+\lambda \sum_{i=1}^{n}\left|\alpha_{i}\right|
$$

em que $\rho_{\tau}(u)=u(1-I(u<0))$ é uma função ponderação linear piecewise, $u$ o resíduo e $I()$ uma função indicador, conforme Koenker e Basset (1978). ${ }^{17}$ O termo $\lambda$ é um parâmetro que penaliza o efeito fixo $\alpha$ na função-objetivo, caso este se distancie de um valor comum (no nosso caso seria zero, ou seja, conforme a equação acima seria $\lambda \sum_{i=1}^{n}\left|\alpha_{i}-0\right|$ ). Esta classe de estimadores penalizados, por meio do $\lambda$, melhora a performance não apenas do efeito fixo, mas também melhora a performance da estimativa do $\beta$ em termos de variabilidade (KOENKER, 2004, 2005). A escolha deste parâmetro $\lambda$, segundo Koenker (2004) e Lamarche (2007), permanece ainda como um problema em aberto nesta literatura. ${ }^{18}$ Os pesos $w_{k}$ ponderam o efeito relativo de cada um dos $q$ quantis $\left\{\tau_{1}, \ldots, \tau_{q}\right\}$ na estimação dos parâmetros. Adotaremos pesos constantes iguais a $1 / q$ (LAMARCHE, 2007), e estimaremos os quantis 0.05 a 0.95 , em intervalos espaçados de 0.05 . Assim, $q=19$.

Para obter os erros padrão decidimos utilizar uma técnica de reamostragem, baseada em um bootstrap para dados em painel. Assim, nos basearemos na estratégia de Lamarche (2007), que utiliza um bootstrap de painel descrito em Cameron e Trivedi (2005, p. 708), mas aplicado para regressões quantílicas. Assim, procuramos minimizar o erro padrão médio, baseado em Lamarche (2007, p. 9):

$$
g(\lambda)=\frac{1}{q} \sum_{t=1}^{T}\left(\frac{1}{B-1} \sum_{b=1}^{B}\left(\bar{\beta}_{7 b}\left(\tau_{j}, \lambda\right)-\overline{\widehat{\beta}}_{7 b}\left(\tau_{j}, \lambda\right)\right)^{2}\right)^{1 / 2}
$$

em que, $\overline{\widehat{\beta}}_{7 b}\left(\tau_{j}, \lambda\right)=\frac{\sum_{b=1}^{B} \widehat{\beta}_{7 b}\left(\tau_{j}, \lambda\right)}{B}$ é a média sobre as $B$ estimativas de bootstrap de $\beta_{7}$ (estimador da variável trat ${ }^{*} d$ mest). O bootstrap para painel é feito por meio da reamostragem com reposição sobre a unidade de cross-section $(i)$, ou seja, a reamostragem é sobre os dados $\left\{\left(y_{i}, x_{i}\right), i=1, \ldots, n\right\}$ - Assim, segundo Cameron e Trivedi (2005), teremos um total de $B$ pseudo-amostras e para cada uma inferimos por meio de (3) o estimador $\bar{\beta}_{7 b}$. Assim, as estimativas (4) do erro padrão médio são feitas para um grid de valores de $\lambda$, de 0.1 até 3 ou 4 , de 0.1 em 0.1 . Após obter estas estimativas, as aproximamos por meio de uma função $(\hat{g}(\lambda))$ spline de alisamento cúbica (cubic smoothing spline). Os gráficos do Painel 1, a seguir, mostram as estimativas desta função $\hat{g}(\lambda)$ para o RJ e RS, ambos utilizando SP como controle.

17 Note da equação (3) que, se $\lambda \rightarrow 0$, reduziremos o estimador penalizado ao estimador puro de efeitos fixos. Agora, quando $\lambda \rightarrow$ $\infty$, então $\alpha_{\mathrm{i}} \rightarrow 0$, ou seja, uma estimativa de um modelo sem controlar para efeitos fixos (KOENKER, 2004, 2005). Assim, $\alpha$ e $\beta$ pertencem a uma classe mais geral de estimadores, chamados estimadores de penalização.

18 Lamarche (2006, apud LAMARCHE, 2007) mostra que, sob certas condições de regularidade, os estimadores do vetor $\beta(\tau, \lambda)$ são assintoticamente não viesados e gaussianos. Assim, como o estimador é não-viesado, o $\lambda$ ótimo $\left(\lambda^{*}\right)$ é o que minimiza a variância assintótica. Se $\alpha \sim \mathrm{N}\left(0, \sigma_{\alpha}\right)$ e u $\sim \mathrm{N}\left(0, \sigma_{\mathrm{u}}\right)$, tal que $\alpha$ e u são independentes entre si, então $\lambda^{*}=\sigma_{\mathrm{u}} / \sigma_{\alpha}(\mathrm{KOENKER}$, 2004, 2005). No entanto, este é um problema em aberto, como apontado, pois a estimação da própria matriz de variância assintótica depende da escolha de $\lambda$. Por isso, inferimos os erros padrão por bootstrap. 
Painel 1 - Erro padrão médio e perfil estimado por meio da função spline

\section{Rio de Janeiro}
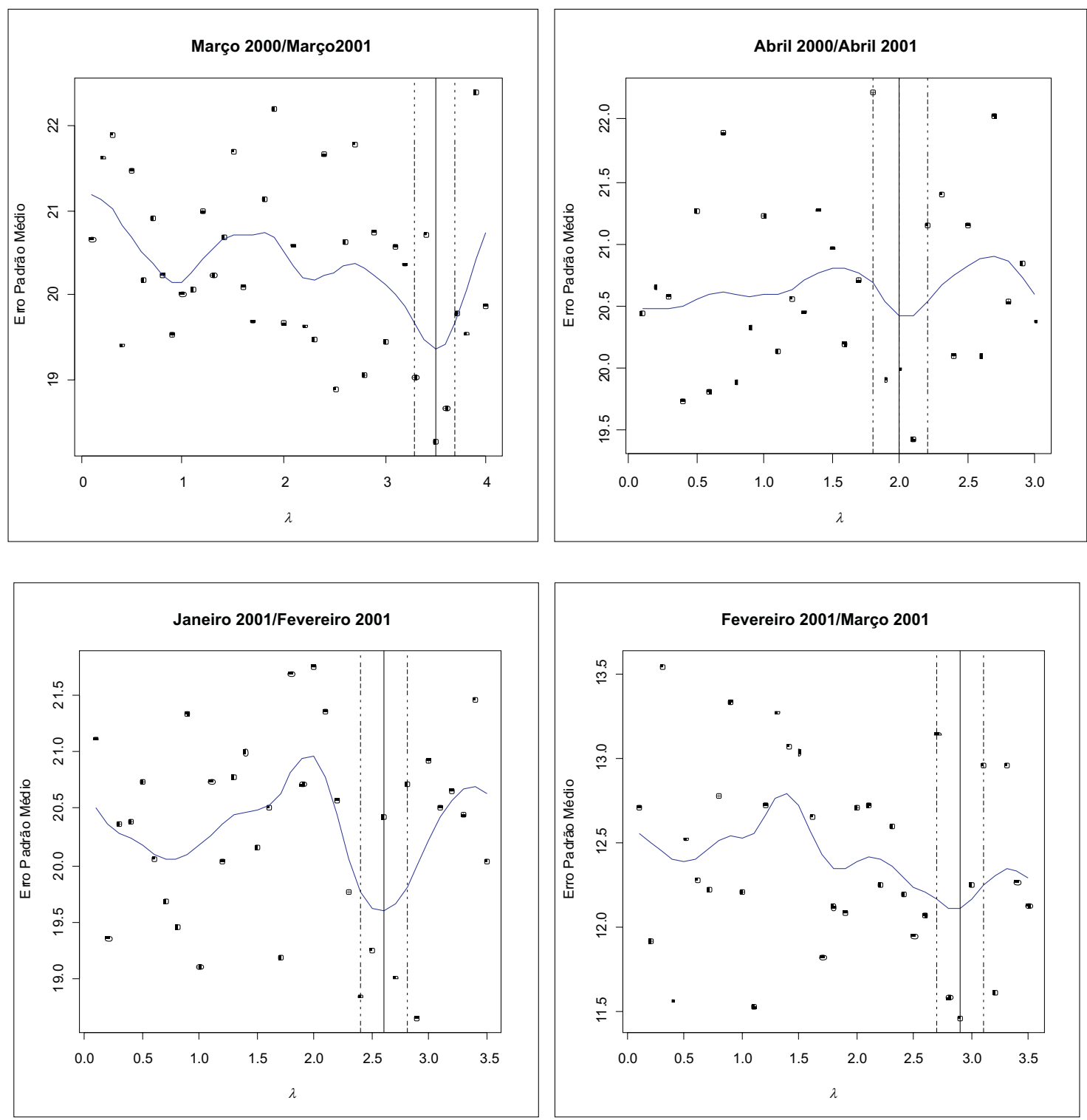


\section{Rio Grande do Sul}
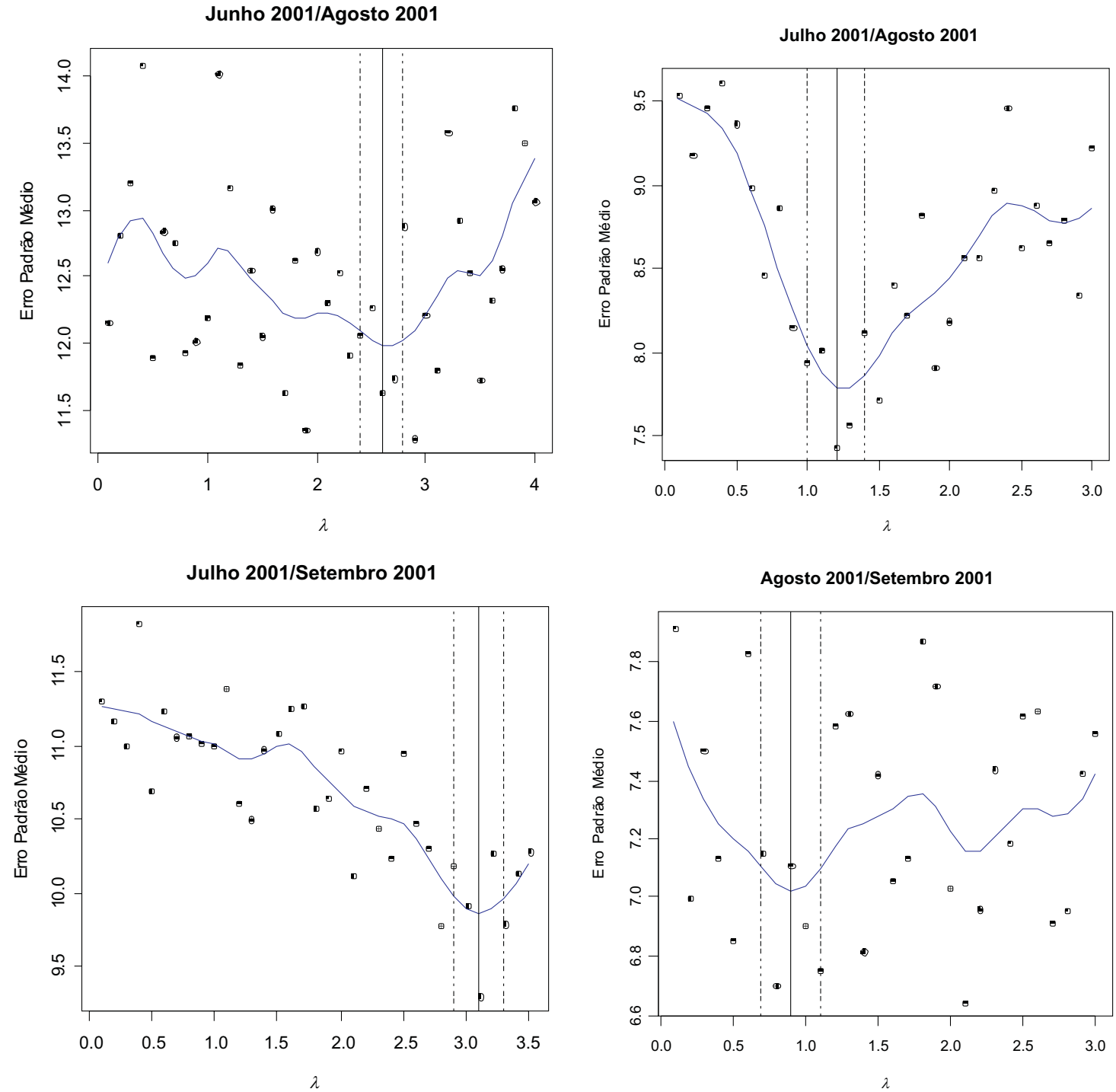

Os erros padrão médios foram obtidos após 100 replicações de bootstrap para dados em painel. A linha vertical contínua refere-se ao valor mínimo do $\lambda$ (ótimo) no qual minimizamos o erro padrão médio. As linhas tracejadas referem-se a uma vizinhança de $0.2 \mathrm{em}$ torno do $\lambda$ ótimo. Assim, tomamos o menor $\lambda$ em torno desta vizinhança, denotado por $\lambda^{*}$, procedimento similar realizado por Lamarche (2007). Estes valores são: 
Tabela 5 - Valores de $\lambda^{*}$

\begin{tabular}{ccccc}
\hline RJ & Mar 2000/Mar 2001 & Abr 2000/Abr 2001 & Jan 2001/Fev 2001 & Fev 2001/Mar 2001 \\
\hline$\lambda^{*}$ & 3.5 & 2.1 & 2.4 & 2.9 \\
\hline RS & Jun 2001/Ago 2001 & Jul 2001/Ago 2001 & Jul 2001/Set 2001 & Ago 2001/Set 2001 \\
\hline$\lambda^{*}$ & 2.6 & 1.2 & 3.1 & 0.8 \\
\hline
\end{tabular}

\subsection{Resultados}

Os gráficos a seguir apresentam o estimador $\widehat{\beta}_{7}\left(\tau, \lambda^{*}\right)$ (da variável trat $*$ dmest $)$ obtido por meio de (3) para o $\lambda^{*}$ selecionado acima, em função dos quantis $(0.05$ a 0.95 , em intervalos espaçados de 0.05). Adicionalmente, incluímos o coeficiente de efeitos fixos da regressão da média condicional (EF). Ressaltamos que os quantis de renda que são teoricamente mais afetados pela lei (binding) situam-se entre 0.05 e 0.25 para as ocupações do RJ, e entre 0.05 e 0.3 para as ocupações do RS, pois este intervalo abrange os agentes que recebem entre o salário mínimo e um pouco acima do maior piso estadual, conforme Tabelas A1 e A2 do Apêndice.

Os coeficientes de efeitos fixos para todos os painéis são não significativos a $5 \%$ e não captam as mudanças nos quantis binding. Assim, a análise a seguir, tanto para RJ como RS, é para os coeficientes das regressões quantílicas.

Rio de Janeiro - Observamos do primeiro gráfico a seguir que, quando comparamos RJ com SP, de março de 2000 para março de 2001, ${ }^{19}$ houve um aumento do gap não significativo em favor de SP em quase todos quantis. Comparando abril de 2000 com abril de 2001, observamos um aumento muito pequeno e não significativo em favor do RJ nos quantis binding de 0.1 a 0.25 . Estes resultados mostram que: (i) a maioria dos períodos comparados apresenta o efeito de um aumento do gap maior em favor do RJ, mas estatisticamente nulo, principalmente nos quantis binding; (ii) o único efeito positivo significativo em favor do RJ é oriundo do efeito do décimo-terceiro salário que o trabalhador recebe em dezembro/janeiro, e (iii) para os quantis mais elevados, com exceção dos períodos de comparação janeiro 2001/fevereiro 2001 (efeito décimo-terceiro), o efeito é estatisticamente nulo, não caracterizando o chamado efeito spillover.

19 Vale ressaltar que reportamos os meses nos quais foi realizada a pesquisa da PME, mas os rendimentos efetivamente recebidos pelos trabalhadores referem-se sempre ao mês anterior. Então, o salário imputado pela pesquisa no mês de março refere-se ao salário recebido no mês de fevereiro. 


\section{Painel 2 - Estimativas ${ }^{20}$ do coeficiente de "diferenças em diferenças" do estimador (3) do RJ ${ }^{21}$}
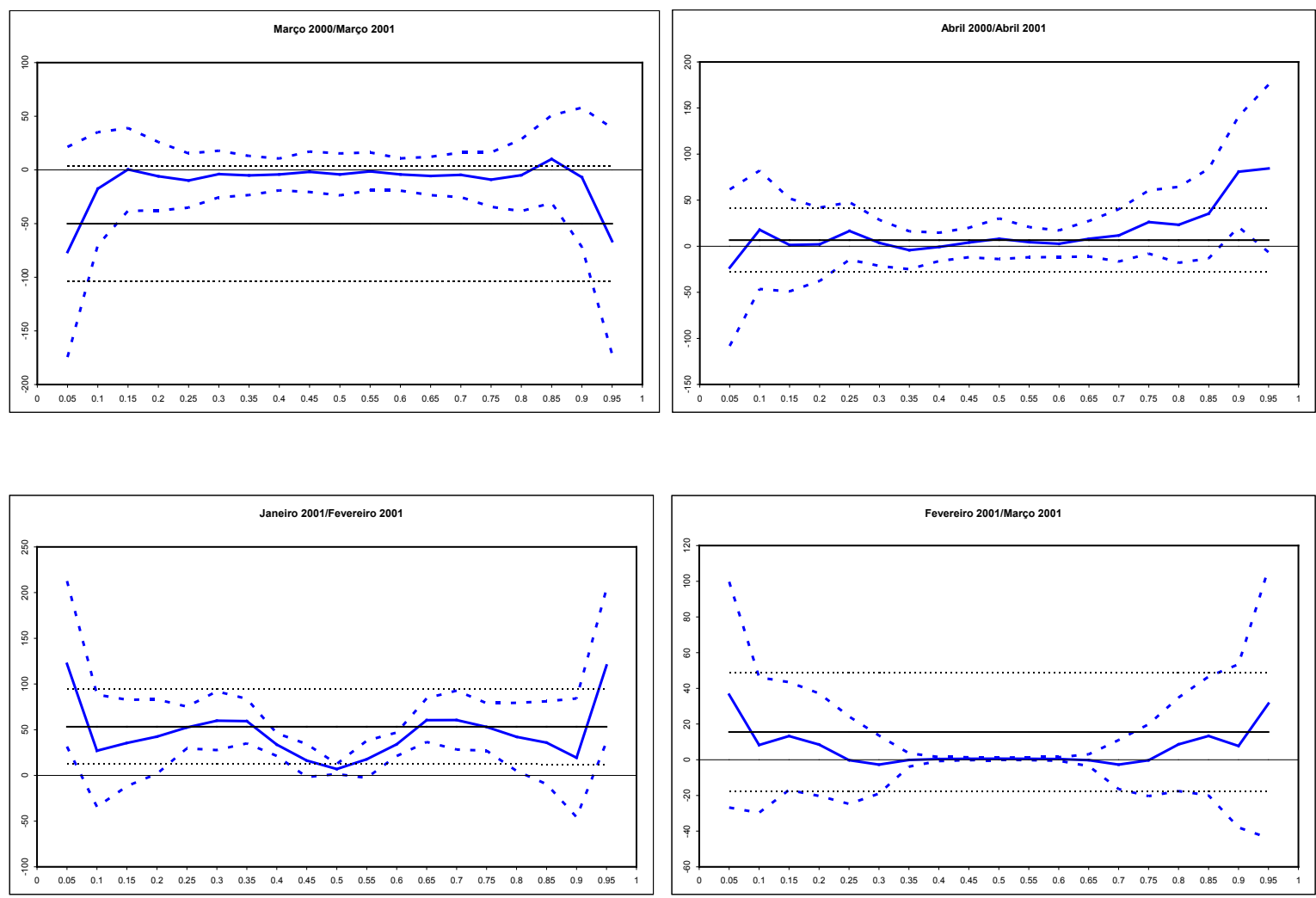

Rio Grande do Sul - Como para o RJ, observa-se que o efeito é nulo e, para os períodos que passariam a vigorar mais efetivamente a lei (julho 2001/setembro 2001 e agosto 2001/setembro 2001), observa-se um efeito positivo, mas não significativo nos quantis binding. Assim, ressalta-se que junho2001/agosto2001 provavelmente não consegue captar efeitos da lei, bem como julho2001/ agosto2001. Isso porque o período final refere-se a rendimentos de julho de 2001 e a lei provavelmente foi mais efetiva a partir de agosto, no qual a PME capta os rendimentos deste mês a partir de setembro. Estes gráficos foram plotados para captar alguma possível expectativa de antecipação por parte dos empregadores em relação à fixação da nova legislação. Este critério é mais factível para o RS, pois a fixação de seus pisos foi no meio do ano, abstraindo-se efeitos de salário mínimo e décimo-terceiro. E, por fim, como observado para o RJ, para os quantis mais altos, o efeito é também não significativo, sem evidência do efeito spillover.

20 Nos gráficos a seguir das estimativas das regressões quantílicas, está incluído o intervalo de confiança (linha tracejada) a $95 \%$. A linha azul contínua é o valor do coeficiente $\beta_{7}\left(\tau, \lambda^{*}\right)$ da regressão quantílica por quantil. A linha preta é o coeficiente de efeitos fixos, juntamente com o seu intervalo de confiança em tracejado, também a $95 \%$.

21 O número de observações destas regressões variou de 2620 a 3170. 


\section{Painel 3 - Estimativas ${ }^{22}$ do coeficiente de "diferenças em diferenças" do estimador (3) do RS ${ }^{23}$}
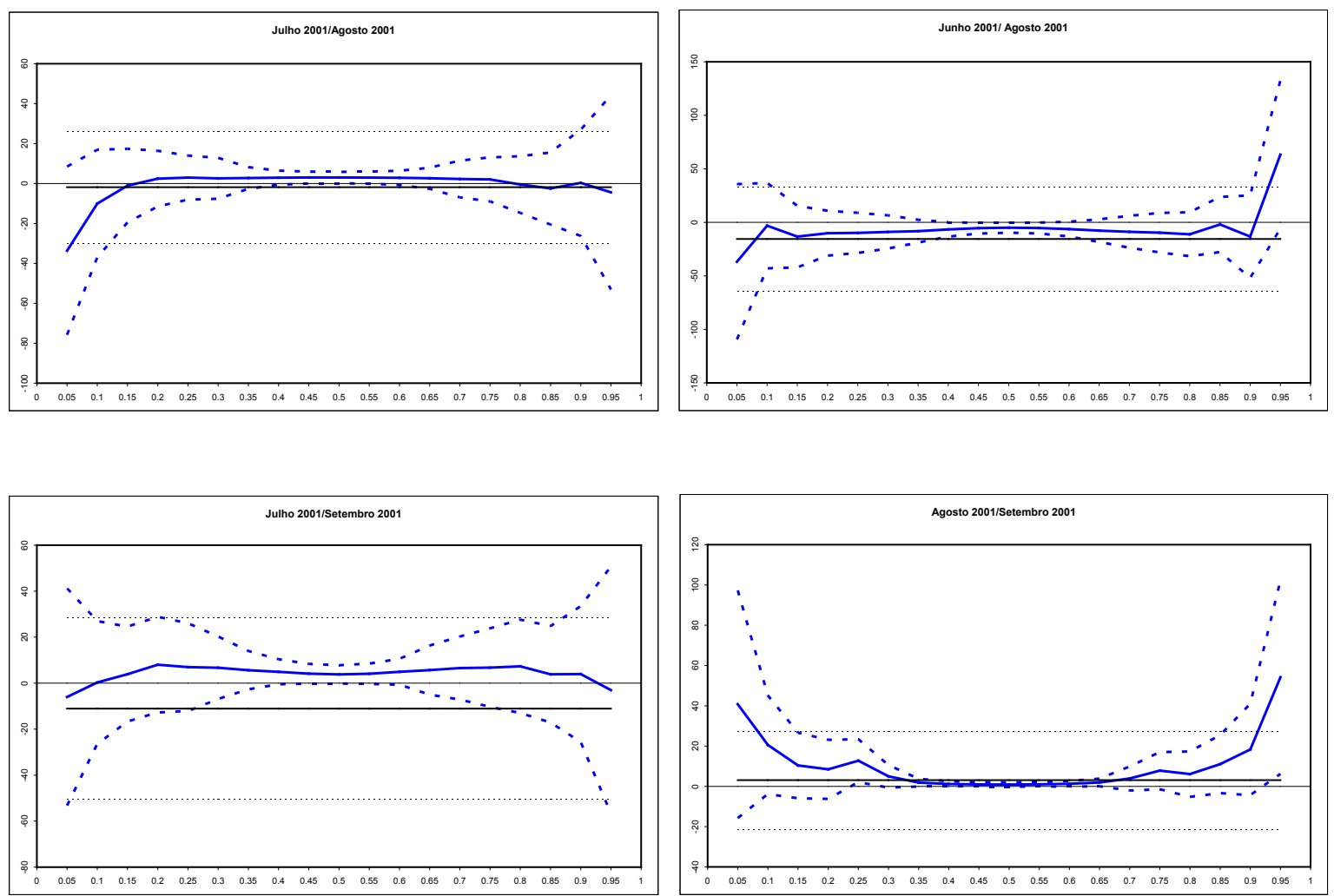

É importante destacar a magnitude diferenciada dos intervalos de confiança (ICs) em relação a diferentes quantis: bem reduzidos em torno da mediana e bem altos nos extremos. Isto pode ser devido a três fatores que estão relacionados: (i) aos períodos analisados, (ii) o efeito-numerário do salário mínimo, (iii) efetividade da lei.

Em relação aos gráficos do Painel 2 (fev/2001-mar/2001 para RJ) e do Painel 3 (todos os gráficos para o RS), os quantis em torno de 0.3 a 0.7 (os quais apresentam ICs bem reduzido) são os quantis de salário que captam o efeito-numerário do salário mínimo, ou seja, os trabalhadores que recebem múltiplos de 2 e 3 salários mínimos ou até mesmo 2.5 salários mínimos (estes quantis podem ser conferidos nas Tabelas A1 e A2 no Apêndice 2). Este efeito é percebido em todos os Estados brasileiros conforme já estudado por Neri et al. (2000). Assim, é de se esperar que não haja uma alteração do gap salarial (diferença entre o salário do indivíduo e o salário mínimo) maior para o RJ/RS em relação a SP (para os grupos ocupacionais definidos na legislação, que tendem a receber menores salários, pois são de baixa qualificação e assim mais sujeitos ao efeito-numerário), principalmente para os períodos analisados destes gráficos, ou seja, para períodos curtos, de 1 ou 2 meses. Caso a lei estadual fosse efetiva, poder-se-ia verificar algum efeito spillover e, em específico, algum efeito-numerário do piso estadual, o que geraria um efeito positivo e significativo nestes quantis

22 Nestes gráficos das estimativas das regressões quantílicas está incluído o intervalo de confiança (linha tracejada) a 95\%. A linha azul contínua é o valor do coeficiente $\beta_{7}\left(\tau, \lambda^{*}\right)$ da regressão quantílica por quantil. A linha preta é o coeficiente de efeitos fixos, juntamente com o seu intervalo de confiança em tracejado, também a $95 \%$.

23 O número de observações destas regressões variou de 4042 a 6764. 
(mas como citado anteriormente não observamos a inexistência do efeito spillover). Logo, os ICs são pequenos, pois quase não existe variabilidade da variação destes gaps.

Para os quantis de 0.05 a 0.3 , estes quantis abrangem a efetividade do salário mínimo federal e, principalmente, a possível efetividade dos pisos estaduais, ou seja, indivíduos que recebem de 1 salário mínimo até o maior piso. Estes quantis apresentam ICs mais elevados para todos os gráficos, o que pode ser devido a algum efeito isolado da efetividade da lei dos pisos estaduais (podendo tanto ser positivo ou negativo, mas não significativo, pois a efetividade da lei é muito baixa conforme discutido no último parágrafo desta subseção) ou uma mudança isolada da efetividade do salário mínimo a favor do RJ/RS ou de SP para as ocupações da lei. Estes efeitos isolados podem gerar uma maior variabilidade e conseqüentemente um maior IC.

Para os quantis mais elevados (acima de 0.7), os ICs são elevados, devido provavelmente ao menor número de observações nestes quantis, o que pode gerar uma maior variabilidade nas estimativas e conseqüentemente maiores ICs.

Em relação ao terceiro gráfico do Painel 2 (janeiro2001-fevereiro2001 para RJ), as explicações dos parágrafos anteriores podem não se aplicar, pois, conforme destacado anteriormente, esse período capta efeitos do décimo-terceiro salário.

Em relação aos dois primeiros gráficos do Painel 2 (março2000-março2001, abril2000abril2001 do RJ), os períodos analisados são espaçados em um ano e, entre estes períodos, houve o reajuste do salário mínimo de 2000, o que pode ter gerado uma maior variabilidade no efeitonumerário para os quantis medianos (entre 0.3 e 0.7 ) entre as ocupações da lei do RJ em relação a SP e, conseqüentemente, na alteração do gap. Porém, mesmo assim, observa-se um efeito estatisticamente nulo, como seria previsto, conforme descrito acima. Para os quantis extremos, é válida a mesma explicação dos outros gráficos.

Assim, se a lei fosse perfeitamente efetiva ( $\lambda k$ próximo de 1$)$, esperar-se-ia que este aumento fosse estatisticamente maior e significativo nos Estados de tratamento (RJ e RS). Entretanto, segundo o modelo de equilíbrio geral de Yaniv (2006), se o incentivo por parte do governo é insuficiente $(1>\lambda k>0)$ para induzir o cumprimento total da lei (mas positivo), o nível salarial deveria ter se reduzido, ou seja, um aumento do diferencial salarial a favor do grupo de controle, mas mesmo assim, o efeito da alteração do gap é estatisticamente nulo. Assim, a evidência apresentada nesta subseção indica, segundo a Figura 1, que as curvas de oferta e demanda tiveram um deslocamento praticamente nulo. Esta evidência de alto descumprimento pode ser devida a um baixo nível de efetividade da legislação ( $\lambda k$ próximo de zero, como destacamos no fim da Subseção 2.1). Logo, segundo Yaniv (2006) e os outros modelos teóricos apresentados na Subseção 2.1, dever-se-ia esperar um impacto nulo no emprego. Tal análise é realizada na próxima subseção.

\subsection{Impacto sobre o nível de emprego}

Nesta subseção analisamos o impacto sobre o nível de emprego para o grupo de tratamento, incluindo apenas as pessoas que são empregadas em uma das categorias profissionais abrangidas pelas leis estaduais e cujo salário na data base era maior do que o salário mínimo federal e menor do que o piso salarial; ou seja, consideramos no grupo de tratamento apenas os quantis binding. 


\section{Modelo econométrico diferenças em diferenças}

Na especificação do modelo, consideramos como variável dependente o status ocupacional do indivíduo $i$ no tempo $t$. Ressaltamos que consideramos, no período inicial, apenas os trabalhadores que estavam empregados em ocupações definidas pela lei. Assim, este status ocupacional foi definido de tal forma a captar o impacto da legislação na passagem de indivíduos empregados no setor formal ou informal destas ocupações para o Estado de desemprego e do setor formal para o setor informal ou desemprego. Destacamos que a segunda mudança pode ocorrer, pois as firmas evitariam a legislação simplesmente migrando para o setor desregulado da economia, ou os trabalhadores, devido a alguma demissão pela imposição dos pisos, poderiam buscar recolocação no mercado de trabalho informal nas mesmas ocupações da lei (CARD; KRUEGER, 1995). Assim, o modelo a ser estimado terá duas especificações, sendo definido como:

$\operatorname{emp}_{k, i, t}=\alpha_{1}+\alpha_{2} \cdot \operatorname{sexo}_{i, t}+\alpha_{3} \cdot$ idade $_{i, t}+\alpha_{4} \cdot \operatorname{escol}_{i, t}+\alpha_{5} \cdot \operatorname{trat}_{i, t}+\alpha_{6 t}+c_{i}+u_{i, t}, \operatorname{com} t=0,1$ e $k=1,2$,

em que sexo é uma variável dummy para sexo, idade é a idade do indivíduo, escol é a escolaridade medida em grau de ensino concluído (fundamental, médio, superior ou pós-superior) e as outras variáveis são:

$\operatorname{emp}_{1, i, t}=\left\{\begin{array}{l}0, \text { se o indivíduo } i \text { está empregado no setor formal ou informal em } t \\ 1 \text {, se o indivíduo } i \text { está desempregado (mas pertencente a PEA) em } t\end{array}\right.$

$e m p_{2, i, t}=\left\{\begin{array}{l}0, \text { se o indivíduo } i \text { está empregado no setor formal em } t \\ 1 \text {, se o indivíduo } i \text { está empregado no setor informal ou desempregado (mas pertencente a PEA) em } t\end{array}\right.$

trat $_{i, t}=\left\{\begin{array}{l}0, \text { se o indivíduo } i \text { pertence ao grupo de controle } \\ 1, \text { se o indivíduo } i \text { pertence ao grupo de tratamento }\end{array}\right.$

As variáveis explicativas se referem unicamente a características observadas do indivíduo (sexo, idade e escolaridade) e uma variável dummy que identifica se a pessoa pertence ao grupo de controle ou grupo de tratamento (RJ ou RS). Além disso, incluímos um termo de efeito fixo $\left(c_{i}\right)$ para captar outras características do indivíduo que não são observáveis, conforme já discutido na subseção anterior. Inclui-se também um efeito temporal, $\alpha_{6 t}$, devido a algum fator comum entre os Estados, mas que se alterou de um período para outro.

Mais especificamente, em relação à variável trat $_{i, t}$, esta recebe valor zero se pertence ao grupo de controle (SP) em $t$, que está empregado em alguma das ocupações definidas na lei do RJ e RS. Como todos nos períodos anteriores à lei estão no grupo de controle, recebem valor zero e consideramos apenas os empregados neste período. Passando para o período após a promulgação da lei, temos que os agentes podem passar para os seguintes estados de natureza: permanecer empregado na mesma categoria profissional definida na lei, passar para outra categoria profissional definida na lei, passar para alguma ocupação não definida na lei ou ficar desempregado. E a variável recebe valor um no período pós-lei para os agentes do grupo de tratamento (RJ e RS), e zero para o do grupo de controle (SP).

Para produzir estimativas consistentes, deveríamos assumir que $c_{i}$ não é correlacionado com trat $_{i, t}$, visto que o termo errático pode ser escrito como $v_{i t}=c_{i}+u_{i t}$. Assim, não basta garantir 
a não-correlação em relação à $u_{i t}$, pois, se for $\operatorname{com} c_{i}$, o estimador será viesado e inconsistente (HAUSMAN; TAYLOR, 1981). Assim, se diferenciarmos, $c_{i}$ assumirá:

$$
\begin{aligned}
\Delta \operatorname{emp}_{k, i, t} & =\alpha_{2} \cdot \Delta \operatorname{sexo}_{i, t}+\alpha_{3} \cdot \Delta \text { idade }_{i, t}+\alpha_{4} \cdot \Delta \operatorname{escol}_{i, t}+\alpha_{5} \cdot \Delta \text { trat }_{i, t}+\Delta \alpha_{6 t}+\Delta u_{i, t} \\
& =\left(\alpha_{3}+\alpha_{7}\right)+\alpha_{5} \cdot \Delta \text { trat }_{i, t}+\Delta u_{i, t}, \operatorname{com} t=1 \text { e } k=1,2
\end{aligned}
$$

Desta forma, a variável $\Delta$ tratamento $_{i, t}$ é uma variável dummy com valor 1 , se o indivíduo mora no RJ ou RS, e que vale 0 , se a pessoa mora em SP, de forma que o estimador de $\alpha_{5}$ é o conhecido estimador de diferenças em diferenças. Além disto, a variável sexo não muda ao longo do tempo e assim desaparece. Ressalta-se que poucas pessoas (ocupadas no período anterior à promulgação da lei nas profissões definidas na lei) mudaram de escolaridade de um ano para o outro. ${ }^{24}$ Assim, a variável $\Delta$ escol foi excluída da estimação, pois se apresentou não significativa em uma primeira inferência. Em relação à variável idade, nota-se que: (i) quando os períodos base e final são próximos, sua variação é aproximadamente nula e o coeficiente $\alpha_{3}$ não faz parte do intercepto; (ii) caso os períodos sejam espaçados de um ano para outro, todos mudam um ano de idade e assim $\alpha_{3}$ faz parte do intercepto. E, por fim, $\alpha_{7}=\Delta \alpha_{6 t}=\alpha_{6_{2}}-\alpha_{6_{1}}$. Assumimos também que $\Delta u_{i}$ seja não correlacionada com $\Delta$ trat $_{i}$ ou seja, com exceção da lei, que nenhum fator relativo aos Estados tenha se alterado diferentemente entre a data base e a data final. Os erros padrão reportados são robustos à heterocedasticidade, ajustados, portanto, conforme White (1980).

\section{Resultados}

Nesta seção apresentamos os resultados do modelo de diferenças em diferenças. Os grupos de controle utilizados foram o estado de SP e os trabalhadores do próprio Estado a ser analisado que recebe entre 1.5 e 3 pisos da categoria profissional.

A seguir, apresentamos a Tabela 6 com os resultados da regressão do modelo diferenças em diferenças, descrito na equação (6). ${ }^{25}$ Analisando o efeito da variável tratamento $\left(\Delta\right.$ trat $\left._{i, t}\right)$ sobre a transição de empregado formal ou informal para desempregado, observamos que todos os coeficientes são estatisticamente não significativos, com exceção de um coeficiente que foi significativo a um nível de $10 \%$.

Assim, para a maioria das regressões efetuadas, o efeito do tratamento é estatisticamente não significativo a um nível de significância de 5\%. Este resultado indica que a mudança da legislação não teve impacto no status ocupacional dos indivíduos, isto é, estatisticamente, identificamos que, em indivíduos que inicialmente pertenciam ao mercado formal ou informal, a mudança na legislação não causou uma maior probabilidade de transferência para o desemprego, bem como de transições do segmento formal para o informal ou para o desemprego.

24 Isto ocorreu porque os agentes que estavam trabalhando já tinham terminado seu período de escolarização ou porque a maioria não estuda enquanto permanece no mercado de trabalho.

25 Os resultados da transição de empregado formal para empregado informal ou desempregado segundo data base e data final apontaram para a mesma evidência dos resultados da Tabela 6 e por isso foram omitidos. No entanto, podem ser requisitados aos autores. 
Tabela 6 - Estimativas diferenças em diferenças $\left(\alpha_{6}\right)$ da regressão (6) sobre a transição de empregado formal ou informal para desempregado segundo data base e data final

\begin{tabular}{|c|c|c|c|c|c|c|c|c|c|}
\hline \multicolumn{2}{|c|}{ Rio de Janeiro } & \multicolumn{2}{|c|}{ mar00/mar01 } & \multicolumn{2}{|c|}{ abr00/abr01 } & \multicolumn{2}{|c|}{ jan01/fev01 } & \multicolumn{2}{|c|}{ fev00/mar01 } \\
\hline Controle & Coeficientes & Coef. & Ef. Marg. & Coef. & Ef. Marg. & Coef. & Ef. Marg. & Coef. & Ef. Marg. \\
\hline \multirow{6}{*}{ São Paulo } & Dif-em-Dif & -0.1421 & -0.0203 & $-0.4531^{* *}$ & $-0.0654^{* *}$ & -0.6634 & -0.0347 & -0.3097 & -0.0182 \\
\hline & Desvio Padrão & 0.2356 & 0.0343 & 0.2358 & 0.0348 & 0.4550 & 0.0261 & 0.3833 & 0.0234 \\
\hline & Constante & $-1.3623^{*}$ & - & $-1.2053^{*}$ & & $-1.7116^{*}$ & & $-1.8081^{*}$ & \\
\hline & Desvio Padrão & 0.1752 & - & 0.1546 & & 0.2670 & & 0.2579 & \\
\hline & Pseudo R2 & 0.0027 & & 0.0270 & & 0.0611 & & 0.0142 & \\
\hline & $\mathrm{N}^{0}$ Observações & 255 & & 258 & & 183 & & 202 & \\
\hline \multirow{6}{*}{ Entre $1.5 p$ e $3 p$} & Dif-em-Dif & 0.3216 & 0.0316 & 0.2162 & 0.0182 & 0.0264 & 0.0006 & 0.0687 & 0.0027 \\
\hline & Desvio Padrão & 0.2211 & 0.0228 & 0.2354 & 0.0208 & 0.4494 & 0.0105 & 0.3443 & 0.0140 \\
\hline & Constante & $-1.8400^{*}$ & & $-1.8747^{*}$ & & $-2.4015^{*}$ & & $-2.1865^{*}$ & \\
\hline & Desvio Padrão & 0.1560 & & 0.1540 & & 0.2580 & & 0.1957 & \\
\hline & Pseudo R2 & 0.0145 & & 0.0065 & & 0.0001 & & 0.0006 & \\
\hline & $\mathrm{N}^{0}$ Observações & 398 & & 407 & & 359 & & 395 & \\
\hline \multicolumn{2}{|c|}{ Rio Grande do Sul } & \multicolumn{2}{|c|}{ jun01/ago01 } & \multicolumn{2}{|c|}{ jul01/ago01 } & \multicolumn{2}{|c|}{ jul01/set01 } & \multicolumn{2}{|c|}{ ago01/set01 } \\
\hline Controle & Coeficientes & Coef. & Ef. Marg. & Coef. & Ef. Marg. & Coef. & Ef. Marg. & Coef. & Ef. Marg. \\
\hline \multirow{6}{*}{ São Paulo } & Dif-em-Dif & -0.1765 & -0.0146 & -0.3324 & -0.0276 & -0.1040 & -0.0100 & 0.1771 & 0.0085 \\
\hline & Desvio Padrão & 0.2861 & 0.0244 & 0.2891 & 0.0249 & 0.3304 & 0.0322 & 0.2963 & 0.0140 \\
\hline & Constante & $-1.6862^{*}$ & & $-1.6111^{*}$ & & $-1.6325^{*}$ & & $-2.1497^{*}$ & \\
\hline & Desvio Padrão & 0.2086 & & 0.1957 & & 0.2380 & & 0.2288 & \\
\hline & Pseudo R2 & 0.0045 & & 0.0158 & & 0.0015 & & 0.0047 & \\
\hline & Nº Observações & 269 & & 266 & & 175 & & 396 & \\
\hline \multirow{6}{*}{ Entre $1.5 p$ e $3 p$} & Dif-em-Dif & 0.0864 & 0.0056 & 0.1962 & 0.0098 & $0.5604^{* *}$ & 0.0304 & 0.3784 & 0.0149 \\
\hline & Desvio Padrão & 0.2414 & 0.0162 & 0.2504 & 0.0139 & 0.2966 & 0.02091 & 0.2508 & 0.0115 \\
\hline & Constante & $-1.9491^{*}$ & & $-2.1397^{*}$ & & $-2.2969^{*}$ & & $-2.3509^{*}$ & \\
\hline & Desvio Padrão & 0.1415 & & 0.1325 & & 0.1887 & & 0.1657 & \\
\hline & Pseudo R2 & 0.0010 & & 0.0046 & & 0.0422 & & 0.0210 & \\
\hline & Nº Observações & 511 & & 710 & & 467 & & 740 & \\
\hline
\end{tabular}

Fonte: Estimativas feitas a partir dos dados da PME.

Notas: $(1) *$ Rejeita hipótese nula a 5\%, * Rejeita hipótese nula a 10\%. Desvio Padrão em negrito. Coef. $=$ Coeficiente, Ef. Marg. = Efeito Marginal. A primeira data é a data base e a segunda data é a data final. Por exemplo: mar00/mar01. mar00 (março de 2000) é a data base e mar01 (março de 2001) é a data final.

(2) Os controles utilizados foram os trabalhadores em ocupações definidas na legislação (descritas no Apêndice 1) dentro do Estado de SP (São Paulo) e do próprio Estado em que a legislação foi definida (RJ ou RS), mas que recebe entre 1.5 e 3 pisos salariais estaduais (entre $1.5 \mathrm{p}$ e $3 \mathrm{p}$ ).

(3) O Coeficiente Dif-em-Dif refere-se ao coeficiente estimado diferenças em diferenças ( $\alpha 5)$ da equação (6).

Entretanto, a metodologia de diferenças em diferenças não é válida se as diferenças entre o grupo de tratamento e o grupo de controle não for apenas a causada por diferentes marcos legais. Poder-se-ia argumentar que fatores relativos aos Estados tenham se alterado diferentemente entre a data base e a data final, o que pode causar um problema de variáveis omitidas na regressão. Um indicativo disto seria o baixo valor das estatísticas $t$. Entretanto, poucas regressões apresentaram 
um valor para a estatística $t$ muito baixo. Assim, o impacto sobre o nível de emprego foi nulo pela imposição da lei.

De qualquer forma, aqui se levanta outra suspeita, de que este impacto poderia estar mais de acordo com modelos de monopsônio, embora este modelo parta da hipótese de cumprimento total à lei do salário mínimo, prevendo, assim, um aumento no nível salarial e simultaneamente um aumento (não-redução) no nível de emprego, dado um aumento pequeno no salário mínimo (CARD; KRUEGER,1995, 1994; CARD, 1992A, 1992B; KATZ; KRUEGER, 1992). No entanto, essas evidências não se aplicam, pois: (i) conforme descrito na subseção anterior, obtivemos um impacto nulo da lei sobre o gap, e (ii) verificamos, a partir da Tabela 1, que os pisos estaduais salariais proporcionaram um aumento significativo em relação ao salário mínimo. Para o RJ e RS, houve um aumento de quase $50 \%$ e $40 \%$, respectivamente. Assim, esta evidência de nulidade no nível do emprego, ante a imposição dos pisos estaduais, nos leva a crer, como evidência adicional, que a lei tem um baixo grau de efetividade. Neste caso, não temos uma evidência de falha do modelo de concorrência perfeita.

Vale ressaltar que, como fator adicional, caso a lei fosse altamente efetiva, esperaríamos uma queda do nível de emprego, dada a predominância do modelo de concorrência perfeita em relação ao efeito do salário mínimo para o Brasil (NERI; MOURA, 2006).

\subsection{Discussão}

As evidências obtidas de um efeito estatisticamente nulo, tanto no nível salarial como no nível de emprego, implicam que o nível de efetividade da lei é muito baixo. Podemos afirmar então que o alto descumprimento à legislação pelas firmas é uma conseqüência da baixa efetividade da lei empregada pelas autoridades. Esta efetividade foi definida na Subseção 2.1 como $\lambda \mathrm{k}$, em que $\lambda$ é a probabilidade de se pegar e punir um empregador violador da lei e $k$ é a penalidade definida pela legislação. Assim, no caso da legislação aqui avaliada, $\lambda k$ provavelmente está muito próxima de zero. Ou seja, o custo efetivo (esperado) de se descumprir a lei que um empregador se depara é muito baixo, devido, provavelmente, a uma combinação de baixa fiscalização (implicando uma baixa probabilidade $[\lambda]$ de se punir o empregador) e reduzida multa $(k)$. Segundo o modelo de Yaniv (2006), apresentado na Subseção 2.1, se a efetividade fosse positiva, esperar-se-ia uma queda no nível salarial do mercado do RJ, mas sem alterações no nível de emprego; porém, como $\lambda k$ está muito próximo de zero, o salário de mercado não se altera. E, segundo a Figura 1, não existe um deslocamento das curvas de oferta e demanda, e com isso o nível salarial se manteria em $w_{0}$.

Outro aspecto, citado na revisão de literatura, que retomamos brevemente é que o grande aumento proporcionado pelos pisos perante o salário mínimo poderia gerar dois efeitos opostos: (i) um maior incentivo ao descumprimento, pois o ganho do subpagamento é maior que o custo esperado (AS; CHANG; EHRLICH, 1985; YANIV, 1998), e (ii) uma maior probabilidade de os trabalhadores denunciarem os empregadores (YANIV, 1998). Entretanto, segundo nossas evidências, o primeiro efeito é predominante, devido à baixa efetividade da lei. 
Outro motivo da baixa efetividade é o alto índice de desemprego quando da fixação dos pisos, pois aumenta o medo de os empregados denunciarem, pois, se perderem o emprego, a probabilidade de recolocação no mercado é menor. ${ }^{26}$

\section{CONCLUSÃo}

Em 2000, o governo federal fixou uma nova lei que permitiu aos Estados fixarem pisos salariais acima do salário mínimo. Os Estados do RJ e RS adotaram essa lei a partir de 2001. A nova lei fornece um experimento útil ao reajustar de maneira diferenciada entre Estados e grupos profissionais, oferecendo uma fonte de variabilidade potencialmente exógena para estimação dos seus impactos. Outra vantagem é isolar os efeitos de mudanças de um preço mínimo sobre a força de trabalho dos impactos fiscais exercidos pelo salário mínimo no contexto brasileiro. Listamos, a seguir, as principais evidências empíricas encontradas acerca dos impactos da nova lei sobre o mercado de trabalho: (i) analisando os resultados das regressões, averiguamos um alto índice de evasão da lei por parte das firmas, visto que RJ e RS apresentam uma variação estatisticamente nula do gap em relação à SP, principalmente nos quantis binding; (ii) a lei dos pisos regionais gerou impactos não significativos no emprego, o que pode ser visto como uma evidência adicional da baixa efetividade da lei. Assim, uma interpretação é que a lei não é efetiva, no sentido de não impor custos às firmas que a descumprem.

Ressaltamos que mudanças no salário mínimo e, em particular, nos pisos estaduais, que impactam a distribuição de rendimentos do trabalho, são importantes para efeitos de formulação de políticas econômicas. A lei dos pisos estaduais tem sido debatida como um avanço na política salarial destinada aos trabalhadores da ativa, mas o que verificamos é que ela é pouco efetiva. Esse resultado poderia ser direcionado aos gestores de política, a fim de alterar a lei federal que permitiu aos Estados esta fixação aos governadores estaduais, a fim de definirem uma multa explícita nas leis estaduais ou, ainda, impor uma maior fiscalização aos agentes privados. Em relação a esse último aspecto, dada a existência de uma fiscalização não efetiva, esta tem gerado custos para a economia, visto que as autoridades estaduais estão consumindo recursos em um monitoramento inócuo.

26 Apesar de a denúncia ser anônima no Brasil, os empregadores, após serem punidos a ressarcirem o atraso de pagamento pela fiscalização, terão uma maior probabilidade de demitir os trabalhadores quanto menor o tamanho de sua firma e maior a rotatividade da mão-de-obra do setor da economia no qual está inserido. 


\section{REFERÊNCIAS}

ASHENFELTER, O.; SMITH, R. S. Compliance with the minimum wage law. Journal of Political Economy, 87, n. 2, p. 333-350, 1979.

ALBRECHT, J.; AXEL, Bo An equilibrium model of search unemployment. Journal of Political Economy, 92, n. 5, p. 824-40, 1984.

BROWN, C. Minimum wage laws: are they overrated? Journal of Economic Perspectives, v. 2, n. 3, p. 133-46, 1988.

BROWN, C.; GILROY, C.; KOHEN, A. The effects of the minimum wage on employment and unemployment. Journal of Economic Literature, v. 20, n. 2, p. 487-582, 1982.

BURDETT, K. D.; MORTENSEN, T. Equilibrium wage differentials and employer size. Northwestern: Center for Mathematical Studies in Economics and Management Science, 1989. (Working Paper 860).

CAMERON, A. C.; TRIVEDI, P. K. Microeconometrics: methods and applications. New York: Cambridge University Press, 2005.

CARD, D. Using regional variation in wages to measure the effects of the federal minimum wage. Industrial and Labor Relations Review, v. 46, n. 1, p. 22-37, 1992a.

. Do minimum wages reduce employment? A case study of California, 1987-1989. Industrial and Labor Relations Review, v. 46, n. 1, p. 38-54, 1992b.

CARD, D.; KRUEGER, A. Minimum wages and employment: a case study of the fast-food industry in New Jersey and Pennsylvania. American Economic Review, v. 84, n. 4, p. 772-93, 1994.

. Myth and measurement: the new economics of the minimum wages. Princeton: Princeton University Press, 1995.

CHANG, Y-M; EHRLICH, I. On the economics of compliance with the minimum wage law. Journal of Political Economy, v. 93, n. 1, p. 84-91, 1985.

CORSEUIL, C. H.; CARNEIRO, F. G. Os impactos do salário mínimo sobre emprego e salários no Brasil: evidências a partir de dados longitudinais e séries de Tempo. Rio de Janeiro: IPEA, 2001. (Texto para Discussão, n. 849)

DICKENS, R.; MANNING, A. Spikes and spill-overs: the impact of the national minimum wage on the wage distribution in a low-wage sector. Economic Journal, 114: C95-C101, 2004.

ECKSTEIN, Z.; WOLPIN, K. Estimating a market equilibrium search model from panel data on individuals. Econometrica, v. 58, n. 4, p. 783-808, 1990.

FAJNZYLBER, P. Minimum wage effects throughout the wage distribution: evidence from Brazil's formal and informal sectors. In: ANPEC. Anais do XXIX Encontro Nacional de Economia, 2001.

GRENIER, G. On compliance with the minimum wage law. Journal of Political Economy, v. 90, n. 1, p. 184-187, 1982.

HAUSMAN, J. A.; TAYLOR, W. Panel data and unbservable individual effects. Econometrica, v. 49, n. 6, p. 1377-1398, 1981.

KATZ, L.; KRUEGER, A. The effects of the minimum wage on the fast-food industry. Industrial and Labor Relations Review, v. 46, n. 1, p. 6-2, 1992.

KOENKER, R.; BASSET, G. Regression quantiles. Econometrica, v. 46, n. ???, p. 33-49, 1978. 
KOENKER, R. Quantile regression for longitudinal data. Journal of Multivariate Analysis, v. 91, p. 74-89, 2004.

- Quantile regression. New York: Cambridge University Press, 2005.

LAMARCHE, C. Robust penalized quantile regression estimation for panel data. University of Oklahoma, 2006. Preprint.

. Voucher program incentives and schooling performance in Colombia: a quantile regression for panel-data approach. University of Oklahoma, 2007. Preprint.

LEMOS, S. A menu of minimum wage variables for evaluating wage and employment effects: evidence from Brazil. University College London, 2003. (Working Paper, 03-02).

- A survey of the effects of the minimum wage in Latin America. University of Leicester, 2007. (Working Paper, n. 07/04).

LOTT, J. R.; ROBERTS, R. D. The expected penalty for commiting a crime: an analysis of minimum wage violations. Journal of Human Resources, 30, n. 2, p. 397-408, 1995.

NERI, M.; MOURA, R. L. La institucionalidad del salario mínimo en Brasil. In: MARINAKIS, A; VELASCo, J. (Ed.) Para qué sirve el salario mínimo? Elementos para su determinación en los países del Cono Sur. Santiago: OIT, cap. III, 2006, p. 105-158.

NERI, M., GONZAGA, G.; CAMARGO, J. M. Distribuição regional da efetividade do salário mínimo no Brasil. Nova Economia, v. 9, n. 2, p. 9-38, 1999. n. 724)

Efeitos informais do salário mínimo e pobreza. Rio de Janeiro: IPEA, 2000. (Texto para Discussão,

NEUMARK, D.; WASCHER, W. Employment effects of minimum and subminimum wage: panel data on state minimum wage laws. Industrial and Labor Relations Review, v. 46, n. 1, p. 55-81, 1992.

NEUMARK, D.; CUNNINGHAM, W.; SIGA, L. The effects of the minimum wage in Brazil on the distribution of family incomes: 1996-2001. Journal of Development Economics, v. 80, n. 1, p. 136-159, 2006.

SILVERMAN, B. W. Density estimation for statistics and data analysis. London: Chapman \& Hall, 1986.

SOARES, S. S. D. O impacto distributivo do salário mínimo: a distribuição individual dos rendimentos do trabalho. Economia Aplicada, v. 8 , n. 1, p. 47-76, 2004.

SQUIRE, L.; SUTHIWART-NARUEPUT, S. The impact of labor market regulations. World Bank Economic Review, v. 11, n. 1, p. 119-143, 1997.

STEWART, M. B. The impact of the introduction of the u.k. minimum wage on the employment probabilities of low-wage workers. Journal of the European Economic Association, v. 2, n. 1, p. 67-97, 2004.

WEIL, D. Public enforcement/private monitoring: evaluating a new approach to regulating the minimum wage. Industrial and Labor Relations Review, v. 58, n. 2, p. 238-257, 2005.

WHITE, H. A Heteroskedasticity-consistent covariance matrix estimator and a direct test for heteroskedasticity. Econometrica, v. 48, n. 4, p. 817-838, 1980.

YANIV, G. Minimum wage noncompliance and the employment decision. Journal of Labor Economics, 19, n. 3, p. 596-603, 2001.

. Minimum wage compliance and the labor demand curve. Journal of Economic Education, 35, n. 3, p. 290-294, 2004a.

. Minimum wage noncompliance and the sub-minimum wage rate. Economics Bulletin, v. 10, n. 9, p. 1-7, 2004b. 
. On the employment effect of noncompliance with the minimum wage law. International Review of Law and Economics, v. 26, n. 4, p. 557-564, 2006.

YANIV, G., AWAD, Y.; COHEN, R.; SHAUL, Y. Noncompliance with the minimum wage law in Israel: an empirical investigation. In: $2^{\text {th }}$ INTERNATIONAL RESEARCH CONFERENCE ON SOCIAL SECURITY. Jerusalem, 1998. 


\section{APÊNDICE 1}

\section{Categorias profissionais abrangidas pela lei estadual do RJ - janeiro/2001}

I - R \$ 220,00 - Para empregados domésticos; cozinheiros, garçons e bar-men; lavadeiros e tintureiros; secretárias, datilógrafos e estenógrafos; administradores e capatazes de explorações agropecuárias e florestais; trabalhadores da agricultura e da pecuária; trabalhadores florestais; pescadores; operadores de máquinas e implementos de agricultura, pecuária e exploração florestal; empregados de comércio; trabalhadores de serviços de administração, conservação, manutenção, limpeza de edifícios, empresas comerciais, indústria, áreas verdes e logradouros públicos; trabalhadores de serviços de higiene, saúde, embelezamento; mensageiros; trabalhadores de serviços de proteção e segurança; trabalhadores de serviços de turismo e hospedagem e serventes.

II - R \$223,00 - Para trabalhadores de minas e pedreiras e sondadores; trabalhadores de tratamento da madeira e de fabricação de papel e papelão; fiandeiros, tecelões e tingidores; trabalhadores de curtimento; trabalhadores de preparação de alimentos; trabalhadores de costura e estofadores; trabalhadores da fabricação de calçados e artefatos de couro; cortadores, polidores e gravadores de pedras; encanadores, soldadores, chapeadores, caldeireiros e montadores de estruturas metálicas; vidreiros e ceramistas; trabalhadores de fabricação de produtos de borracha e plástico; confeccionadores de produtos de papel e papelão; pintores; trabalhadores da confecção de instrumentos musicais e produtos de vime e de derivados de minerais não-metálicos; trabalhadores da movimentação e manipulação de mercadorias e materiais, operadores de máquinas de construção civil e mineração; condutores de veículos de transporte e trabalhadores assemelhados e pedreiros.

III - R \$226,00 - Para mestres, contramestres, supervisores de produção e manutenção industrial; operadores de instalações de processamentos químicos; marceneiros e operadores de máquinas de lavrar madeira; trabalhadores de usinagem de metais; ajustadores mecânicos, montadores e mecânicos de máquinas, veículos e instrumentos de precisão; eletricista e eletrônicos; operadores de estações de rádio e televisão e de equipamentos de sonorização e projeções cinematográficas; joalheiros e ourives e trabalhadores de artes gráficas.

\section{Categorias profissionais abrangidas pela lei estadual do RS - julho/2001}

I - de R $\$ 230$ para os seguintes trabalhadores: na agricultura e na pecuária; nas indústrias extrativas; em empresas de pesca; empregados domésticos; em turismo e hospitalidade; nas indústrias da construção civil; nas indústrias de instrumentos musicais e brinquedos; em estabelecimentos hípicos;

II - de R \$ 235 para os seguintes trabalhadores: nas indústrias do vestuário e do calçado; nas indústrias de fiação e tecelagem; nas indústrias de artefatos de couro; nas indústrias do papel, papelão e curtiça; em empresas distribuidoras e vendedoras de jornais e revistas e empregados em bancas, vendedores ambulantes de jornais e revistas; empregados da administração das empresas proprietárias de jornais e revistas; empregados em estabelecimento de serviços de saúde.

III — de R \$ 240 para os seguintes trabalhadores: nas indústrias do mobiliário; nas indústrias químicas farmacêuticas; nas indústrias cinematográficas; nas indústrias da alimentação; empregados no comércio em geral; empregados de agentes autônomos do comércio. 
IV - de $\mathbf{R} \$ 250$ para os seguintes trabalhadores: nas indústrias metalúrgicas mecânicas e de materiais elétricos; nas indústrias gráficas; nas indústrias de vidros, cristais, espelhos, cerâmica de louça e porcelana; nas indústrias de artefatos de borracha; em empresas de seguro privado e capitalização e de agentes autônomos e de seguros privados; em edifícios, condomínios residenciais, comerciais e similares; nas indústrias de joalheria e lapidação de pedras preciosas.

\section{APÊNDICE 2 - ESTATÍSTICAS DESCRITIVAS}

\section{Tabela A1 - Percentis e média dos rendimentos das ocupações do RJ}

\begin{tabular}{|c|c|c|c|c|c|c|c|c|c|c|c|c|c|c|c|c|}
\hline \multirow{3}{*}{$\begin{array}{l}\text { Períodos } \\
\text { Analisados }\end{array}$} & \multicolumn{4}{|c|}{ março/2000-março/2001 } & \multicolumn{4}{|c|}{ abril/2000-abril/2001 } & \multicolumn{4}{|c|}{ janeiro/2001-fevereiro/2001 } & \multicolumn{4}{|c|}{ fevereiro/2001-março/2001 } \\
\hline & \multicolumn{2}{|c|}{ março/2000 } & \multicolumn{2}{|c|}{ março/2001 } & \multicolumn{2}{|c|}{ abril/2000 } & \multicolumn{2}{|c|}{ abril/2001 } & \multicolumn{2}{|c|}{ janeiro/2001 } & \multicolumn{2}{|c|}{ fevereiro/2001 } & \multicolumn{2}{|c|}{ fevereiro/2001 } & \multicolumn{2}{|c|}{ março/2001 } \\
\hline & RJ & SP & RJ & SP & RJ & SP & RJ & SP & RJ & SP & RJ & SP & RJ & SP & RJ & SP \\
\hline média & 635 & 835 & 625 & 874 & 656 & 828 & 673 & 839 & 748 & 954 & 650 & 802 & 641 & 813 & 640 & 795 \\
\hline \multicolumn{17}{|l|}{ percentil } \\
\hline 1 & 106 & 100 & 150 & 82 & 120 & 100 & 150 & 150 & 131 & 110 & 100 & 100 & 101 & 100 & 139 & 100 \\
\hline 5 & 136 & 160 & 151 & 200 & 136 & 180 & 151 & 200 & 151 & 190 & 151 & 180 & 151 & 151 & 151 & 180 \\
\hline 10 & 160 & 220 & 200 & 250 & 170 & 200 & 180 & 250 & 180 & 250 & 171 & 230 & 180 & 200 & 180 & 210 \\
\hline 15 & 182 & 250 & 200 & 300 & 200 & 250 & 200 & 300 & 200 & 300 & 200 & 250 & 200 & 250 & 200 & 250 \\
\hline 20 & 200 & 300 & 250 & 300 & 202 & 300 & 250 & 300 & 220 & 300 & 215 & 300 & 220 & 300 & 226 & 300 \\
\hline 25 & 240 & 300 & 265 & 350 & 250 & 300 & 270 & 300 & 250 & 340 & 240 & 300 & 250 & 300 & 250 & 300 \\
\hline 30 & 250 & 300 & 280 & 350 & 260 & 300 & 300 & 350 & 280 & 350 & 260 & 320 & 260 & 320 & 280 & 350 \\
\hline 50 & 300 & 400 & 350 & 470 & 340 & 400 & 380 & 450 & 377 & 500 & 350 & 400 & 350 & 400 & 350 & 400 \\
\hline 75 & 450 & 660 & 500 & 700 & 500 & 600 & 600 & 700 & 600 & 800 & 505 & 700 & 500 & 650 & 500 & 600 \\
\hline 95 & 1000 & 1300 & 900 & 1500 & 1000 & 1200 & 1000 & 1500 & 1285 & 1540 & 1000 & 1200 & 1000 & 1256 & 1000 & 1256 \\
\hline
\end{tabular}

Fonte: Elaboração própria a partir dos dados da PME.

Notas: 1 . As áreas sombreadas referem-se aos quantis binding salário entre o SM e um pouco acima do maior piso estadual do RJ em $2001 \mathrm{R} \$ 226)$ ).

2. A renda média está em termos reais para fins de comparação entre os Estados, mas os quantis estão em termos norminais que não diferem se estivessem em termos reais) para facilitar a comparação dos valores do SM e pisos dados na Tabela 1. 
Tabela A2 - Percentis e média dos rendimentos das ocupações do RS

\begin{tabular}{|c|c|c|c|c|c|c|c|c|c|c|c|c|c|c|c|c|}
\hline \multirow{3}{*}{$\begin{array}{l}\text { Períodos } \\
\text { Analisados }\end{array}$} & \multicolumn{4}{|c|}{ junho/2001-agosto/2001 } & \multicolumn{4}{|c|}{ julho/2001-agosto/2001 } & \multicolumn{4}{|c|}{ julho/2001-setembro/2001 } & \multicolumn{4}{|c|}{ agosto/2001-setembro/2001 } \\
\hline & \multicolumn{2}{|c|}{ junho/2001 } & \multicolumn{2}{|c|}{ agosto/2001 } & \multicolumn{2}{|c|}{ julho/2001 } & \multicolumn{2}{|c|}{ agosto/2001 } & \multicolumn{2}{|c|}{ julho/2001 } & \multicolumn{2}{|c|}{ setembro/2001 } & \multicolumn{2}{|c|}{ agosto/2001 } & \multicolumn{2}{|c|}{ setembro/2001 } \\
\hline & RS & SP & RS & SP & RS & SP & RS & SP & RS & SP & RS & SP & RS & SP & RS & SP \\
\hline média & 736 & 1004 & 721 & 1003 & 688 & 925 & 690 & 929 & 674 & 892 & 674 & 901 & 685 & 912 & 684 & 907 \\
\hline \multicolumn{17}{|l|}{ percentil } \\
\hline 1 & 100 & 105 & 100 & 100 & 90 & 100 & 100 & 100 & 98 & 100 & 100 & 100 & 100 & 100 & 100 & 100 \\
\hline 5 & 180 & 180 & 180 & 190 & 180 & 180 & 180 & 180 & 180 & 180 & 180 & 180 & 180 & 180 & 180 & 180 \\
\hline 10 & 180 & 220 & 180 & 250 & 180 & 200 & 180 & 200 & 180 & 200 & 200 & 200 & 200 & 200 & 200 & 200 \\
\hline 15 & 200 & 250 & 220 & 280 & 200 & 250 & 220 & 250 & 200 & 250 & 230 & 250 & 230 & 250 & 230 & 250 \\
\hline 20 & 240 & 300 & 250 & 300 & 230 & 290 & 250 & 300 & 240 & 280 & 250 & 300 & 250 & 300 & 250 & 300 \\
\hline 25 & 250 & 300 & 251 & 300 & 250 & 300 & 250 & 300 & 250 & 300 & 250 & 300 & 250 & 300 & 256 & 300 \\
\hline 30 & 280 & 343 & 280 & 350 & 276 & 300 & 280 & 320 & 280 & 300 & 280 & 330 & 280 & 320 & 280 & 320 \\
\hline 50 & 350 & 400 & 350 & 411 & 350 & 400 & 350 & 400 & 350 & 400 & 350 & 400 & 350 & 400 & 350 & 400 \\
\hline 75 & 520 & 700 & 500 & 700 & 500 & 650 & 500 & 681 & 500 & 600 & 500 & 650 & 500 & 630 & 500 & 600 \\
\hline 95 & 1500 & 2000 & 1500 & 2000 & 1359 & 2000 & 1394 & 2000 & 1300 & 1800 & 1340 & 1800 & 1270 & 2000 & 1300 & 2000 \\
\hline
\end{tabular}

Fonte: Elaboração própria a partir dos dados da PME.

Notas: 1. As áreas sombreadas referem-se aos quantis binding salário entre o SM e um pouco acima do maior piso estadual do RS em 2001R \$250)).

2. A renda média está em termos reais para fins de comparação entre os Estados, mas os quantis estão em termos nominais que não diferem se estivessem em termos reais) para facilitar a comparação dos valores do SM e pisos dados na Tabela 1 . 